IZA DP No. 8874

Testing the Validity of Item Non-Response as a Proxy for Cognitive and Non-Cognitive Skills

Sonja C. Kassenboehmer

Stefanie Schurer

Felix Leung

February 2015 


\title{
Testing the Validity of Item Non-Response as a Proxy for Cognitive and Non-Cognitive Skills
}

\author{
Sonja C. Kassenboehmer \\ Monash University and IZA \\ Stefanie Schurer \\ University of Sydney and IZA
}

Felix Leung

University of Sydney
Discussion Paper No. 8874
February 2015

\author{
IZA \\ P.O. Box 7240 \\ 53072 Bonn \\ Germany
}

Phone: +49-228-3894-0

Fax: +49-228-3894-180

E-mail: iza@iza.org

Any opinions expressed here are those of the author(s) and not those of IZA. Research published in this series may include views on policy, but the institute itself takes no institutional policy positions. The IZA research network is committed to the IZA Guiding Principles of Research Integrity.

The Institute for the Study of Labor (IZA) in Bonn is a local and virtual international research center and a place of communication between science, politics and business. IZA is an independent nonprofit organization supported by Deutsche Post Foundation. The center is associated with the University of Bonn and offers a stimulating research environment through its international network, workshops and conferences, data service, project support, research visits and doctoral program. IZA engages in (i) original and internationally competitive research in all fields of labor economics, (ii) development of policy concepts, and (iii) dissemination of research results and concepts to the interested public.

IZA Discussion Papers often represent preliminary work and are circulated to encourage discussion. Citation of such a paper should account for its provisional character. A revised version may be available directly from the author. 
IZA Discussion Paper No. 8874

February 2015

\section{ABSTRACT
Testing the Validity of Item Non-Response as a Proxy for Cognitive and Non-Cognitive Skills ${ }^{*}$

Cognitive and non-cognitive skills are important determinants of labor market outcomes, but are often unobserved. We propose a proxy for these skills derived from item non-response information and a procedure to test its validity. Exploiting a unique data-collection feature of an Australian survey, we find that fraction answered on a self-completion questionnaire fulfils all necessary requirements to be a valid proxy for cognitive skills and outperforms alternative proxies derived from paradata. Fraction answered captures a third of the effect of cognitive ability on wages and education. We provide a simple solution to reduce omitted-variable biase by up to $11 \%$.

JEL Classification: J24, C18, C83, I20, J30

Keywords: paradata, item non-response, proxy-variable approach, cognitive ability, non-cognitive skills, wages, education

Corresponding author:

Stefanie Schurer

School of Economics

The University of Sydney

Sydney

Australia

E-mail: stefanie.schurer@sydney.edu.au

\footnotetext{
* The authors acknowledge financial support from an Australian Research Council Early Career Discovery Program Grant (DE140100463) and the Australian Research Council Centre of Excellence for Children and Families over the Life Course (project number CE140100027). This paper uses unit record data from the Household, Income and Labour Dynamics in Australia (HILDA) Survey, which is a project initiated and funded by the Australian Government Department of Families, Housing, Community Services and Indigenous Affairs (FaHCSIA) and is managed by the Melbourne Institute of Applied Economic and Social Research. The findings and views reported in this paper, however, are those of the authors and should not be attributed to either FaHCSIA or the Melbourne Institute. All authors would like to thank participants of the University of Sydney Microeconometrics and Public Policy Seminar and David Johnston, Frauke Kreuter, Peter Siminski, Agne Suziedelyte, Joachim Winter and Jeffrey Wooldridge for helpful comments.
} 


\section{Introduction}

One of the main goals in economic research is to identify causal relationships between policyrelevant factors and economic outcome variables. Often it is impossible to estimate causal effects because important confounding variables are not observed to the researcher - some of the most frequently mentioned in the applied microeconometric literature are cognitive ability and motivation (e.g. Wooldridge, 2010, p. 282). The reason why measures for cognitive skills are often missing from standard household surveys is that they are time intensive and invasive. Many of the most prominent nationally-representative household surveys, such as the Australian Household, Income and Labour Dynamics Survey (HILDA) or the German Socio-Economic Panel Survey (SOEP), have shied away from introducing cognitive ability tests up until late in their lifespan.

Measures of personality traits, sometimes referred to as non-cognitive skills (Almlund et al., 2011), are less invasive and time intensive to collect. Yet, the broadest instrument to measure non-cognitive skills in adulthood, the Big-Five personality traits, are collected rarely or too late in the lifespan of the study. For instance, two of the most comprehensive cohort studies, the National Longitudinal Study of Adolescent to Adult Health (AddHealth) and the National Child Development Study (NCDS), collected the Big-Five only in their most recent follow up, when subjects were already 30 and 50 years of age, respectively. This late collection makes it difficult for researchers to use the Big-Five measures as inputs into educational-attainment (e.g. Lundberg, 2013) or wage-regression models (e.g. Fletcher, 2013).

We propose to exploit paradata to derive a proxy for unobserved cognitive and non-cognitive skills that can help to reduce omitted-variable biases. Paradata refers to information "captured during the process of producing a survey statistic" (Kreuter, 2013, p. 3). Examples of paradata 
are individual response times and response patterns, interviewer evaluations of the household, the number of contact attempts, and audio or video recordings of interviewer-respondent interactions. Until now, paradata have been used by survey methodologists to evaluate survey quality or costs (Kreuter, 2013), but more recently economists have used paradata to assess, or fix, potential estimation biases in applied economic research (Heffetz and Rabin, 2013; Kleinjans and van Soest, 2014; Behaghel et al., 2015).

In this study we posit that fraction of survey questions answered (referred to as Fraction Answered from hereon) is a valuable source of paradata to learn about a respondent's cognitive and non-cognitive skills. For many years survey methodologists have suggested that item nonresponse is likely to depend on the respondent's (1) knowledge about the topic, (2) judgment of the adequacy of what he or she knows relative to what the question seems to require, and (3) willingness or ability to provide complete reports (Beatty and Herrmann, 2002). ${ }^{1}$ The first two reasons for item non-response are of a cognitive nature, while the third reason is motivational and thus dependent on the respondent's personality. A respondent's general cognitive and verbal ability plays a crucial role in understanding the question and in the decision to respond. The willingness to provide complete reports also depends on a respondent's trust in the interviewer or administering organization, perseverance to complete all questions, and care not to miss a question by accident. If cognitive factors dominate the response behavior, then Fraction Answered should strongly correlate with measures of coding speed, verbal knowledge, or memory. If motivational factors dominate response behavior, then it should strongly correlate with measures of conscientiousness, openness to experience, and agreeableness.

\footnotetext{
${ }^{1}$ Item non-response is different from unit non-response, which is affected by the social environment, the household, and the survey design, including the definition of the sampling frame, the questionnaire design, choice of mode, hiring, selection, and training of interviewers, the length of the data collection period, protocols for contacting sample units, callback rules, etc. (Groves and Couper, 1998).
} 
The aim of this paper is to assess whether Fraction Answered is a valid proxy for either cognitive or non-cognitive skills in the context of standard wage and educational-attainment equations. We propose a three-step testing procedure based on standard statistical methods that assesses the strength, irrelevance, and independence properties of the proxy variable. Special attention will be paid to the question whether the estimation biases introduced through an imperfect proxy exceed the ones introduced through omitting relevant variables (see Wickens, 1972; McCallum, 1972; Aigner, 1974, for theoretical discussions).

For the analysis, we exploit a unique data-collection feature from the Household, Income and Labour Dynamics of Australia (HILDA) survey. The main data collection process is facilitated with professional interviewers who visit the household and interview all household members. A self-completion questionnaire (SCQ) is left with each interviewee to be filled out without help from the interviewer. We construct a measure of item non-response from this SCQ, while all of the outcome and control variables used in the analysis are derived from sections of the survey that do not feed into the item-non-response proxy. Another advantage of the data set is that the SCQ is long enough - for example, it contains up to 258 questions in wave 12 - to obtain meaningful variation in the measure of individual-specific item non-response. The data also provide other paradata that allow us to construct alternative proxy variables and evaluate the strength of Fraction Answered against these alternatives. 


\section{The econometric problem}

\subsection{Assumptions}

In this section we demonstrate the conditions under which even an imperfect proxy causes less bias in the estimated parameters of interest than the omission of the unobserved variable from the model. The mechanics of the proxy-variable approach are similar to the statistical consequences of measurement error (e.g. Bollinger, 2003): the larger the error between the omitted variable and its proxy, the more noise we introduce into the system by using the proxy. Early work on the trade-off between a noisy proxy and omitting a relevant variable recommended that the former is unequivocally preferable to the latter (e.g. Wickens, 1972; McCallum, 1972), especially so in comparison to alternative, available solutions (Aigner, 1974).

We illustrate these trade-offs with an application to the Mincer wage equation adapted from Wooldridge (2003), however the same derivations hold when using educational attainment or any other outcome variable. Let log earnings $\left(Y_{i}\right)$ be a function, for simplicity only, of formal training (years of education, EDU $\left.{ }_{i}\right)$, non-cognitive skills $\left(\mathrm{NCS}_{i}\right)$, and cognitive skills $\left(\mathrm{CS}_{i}\right)$ :

$$
Y_{i}=\beta_{0}+\beta_{1} E D U_{i}+\beta_{2} \text { NCS }_{i}+\beta_{3} C S_{i}+u_{i}
$$

Let's also assume for simplicity that we do not observe cognitive skills (the same derivations hold for assuming that non-cognitive skills are unobserved), so we estimate instead: ${ }^{2}$

\footnotetext{
${ }^{2}$ Our application is different from e.g. Neal and Johnson (1996) in which human capital is considered to be inherently unobservable. Their study used measures from the Armed Forces Qualification Test (AFQT) and the Armed Services Vocational Aptitude Battery (ASVAB) as proxies for acquired human capital. Note, in our application acquired human capital, i.e. level of schooling, is directly and correctly observable, but cognitive ability, a subcomponent of human capital that is not necessarily shaped through the formal education process, is not observed and requires a proxy.
} 


$$
Y_{i}=\beta_{0}^{\prime}+\beta_{1}^{\prime} \mathrm{EDU}_{i}+\beta_{2}^{\prime} \mathrm{NCS}_{i}+u_{i}^{\prime} .
$$

Cognitive skills are likely to positively correlate with measures of non-cognitive skills (mainly openness to experience, see Fletcher and Schurer (2014)) and university education (See Wai, 2013, for an overview). Under the assumption of positive correlations between omitted and included variables and positive values of $\beta_{1}$ and $\beta_{2}$, it is straightforward to show that there is an upward bias in $\hat{\beta}_{1}^{\prime}$ and $\hat{\beta}_{2}^{\prime}$.

Let's assume we have the variable Fraction Answered $F A_{i}$ available to be used as a proxy for $\mathrm{CS}_{i}$ to estimate log earnings as:

$$
Y_{i}=\beta_{0}{ }^{\prime \prime}+\beta_{1}{ }^{\prime \prime} E D U_{i}+\beta_{2}{ }^{\prime \prime} \mathrm{NCS}_{i}+\beta_{3}{ }^{\prime \prime} F A_{i}+u_{i}{ }^{\prime \prime} .
$$

The question is whether the estimates of $\beta_{1}{ }^{\prime \prime}$ and $\beta_{2}{ }^{\prime \prime}$ are closer to $\beta_{1}$ and $\beta_{2}$ than $\beta_{1}{ }^{\prime}$ and $\beta_{2}{ }^{\prime}$, or whether we will make things worse by including $F A_{i}$. Three assumptions must hold for the proxy-variable approach to improve upon the omitted-variable bias.

\section{Assumption 1: Strength}

The proxy must correlate strongly with the unobserved variable $\mathrm{CS}_{i}$ :

$$
\mathrm{CS}_{i}=\delta_{0}+\delta_{1} \mathrm{EDU}_{i}+\delta_{2} \mathrm{NCS}_{i}+\delta_{3} \mathrm{FA}_{i}+v_{i}
$$

$F A_{i}$ correlates with $C S_{i}$ if $\left|\delta_{3}\right|>0$. This condition is equivalent to the strength argument in the context of instrumental variables.

\section{Assumption 2: Irrelevance}


The proxy variable $F A_{i}$ is irrelevant in the main outcome equation Eq. (1) if the unobserved variable $C S_{i}$ is controlled for:

$$
E\left(u_{i} \mid E D U, N C S, C S\right)=E\left(u_{i}\right)=0
$$

and

$$
E\left(u_{i} \mid F A\right)=0
$$

Eq. (6) is equivalent to the validity requirement of an instrumental variable.

\section{Assumption 3: Independence}

The error term $\left(v_{\mathfrak{i}}\right)$ in the proxy equation Eq. (4) is independent of education, non-cognitive skills, and Fraction Answered, or in other words, the average cognitive skill does not vary with education or non-cognitive skills once Fraction Answered is controlled for (strong independence).

$$
\mathrm{E}\left(\mathrm{CS}_{\mathrm{i}} \mid \mathrm{EDU}, \mathrm{NCS}, \mathrm{FA}\right)=\mathrm{E}\left(\mathrm{CS}_{\mathrm{i}} \mid \mathrm{FA}\right)=\delta_{0}+\delta_{3} \mathrm{FA} A_{i}
$$

If $\delta_{1}$ and $\delta_{2}$ do not converge towards zero in Eq. (4), then the plug-in approach to the omittedvariable problem will incur a bias. This will almost certainly occur, because the omitted-variable problem requires fixing only if $\delta_{1} \neq 0$ and $\delta_{2} \neq 0$. The main question is under what condition is the incurred bias through an imperfect proxy no worse or smaller than the omitted-variable bias. It can be shown that the imperfect-proxy biases in the estimated coefficients on education and non-cognitive skills from Eq. (3) are (See Wooldridge, 2003, p. 299): 


$$
\begin{aligned}
& \operatorname{plim}\left(\hat{\beta}_{1}{ }^{\prime \prime}\right)-\beta_{1}=\beta_{3} \delta_{1}, \\
& \operatorname{plim}\left(\hat{\beta}_{2}{ }^{\prime \prime}\right)-\beta_{2}=\beta_{3} \delta_{2},
\end{aligned}
$$

where $\delta_{1}$ and $\delta_{2}$ are obtained from Eq. (4), which we refer to from hereon as long regression. The coefficient $\beta_{3}$ measures the true effect of cognitive skills on earnings $\left(\beta_{3}>0\right)$.

It can also be shown that the omitted-variable biases from Eq. (2) in each case are ${ }^{3}$ :

$$
\begin{aligned}
& \operatorname{plim}\left(\hat{\beta}_{1}{ }^{\prime}\right)-\beta_{1}=\beta_{3} \gamma_{1}, \\
& \operatorname{plim}\left(\hat{\beta}_{2}{ }^{\prime}\right)-\beta_{2}=\beta_{3} \gamma_{2},
\end{aligned}
$$

where $\gamma_{1}$ and $\gamma_{2}$ are obtained from what we refer to as the short regression:

$$
\mathrm{CS}_{i}=\gamma_{0}+\gamma_{1} \mathrm{EDU}_{i}+\gamma_{2} \mathrm{NCS}_{\mathrm{i}}+\gamma_{i} .
$$

The imperfect-proxy bias is smaller than the omitted-variable bias in the coefficients of education and non-cognitive skills if:

$$
\begin{aligned}
& \left|\operatorname{plim}\left(\hat{\beta}_{1}{ }^{\prime}\right)-\beta_{1}\right|>\left|\operatorname{plim}\left(\hat{\beta}_{1}^{\prime \prime}\right)-\beta_{1}\right| \leftrightarrow\left|\gamma_{1}\right|>\left|\delta_{1}\right| \\
& \left|\lim \left(\hat{\beta}_{2}{ }^{\prime}\right)-\beta_{2}\right|>\left|\operatorname{plim}\left(\hat{\beta}_{2}^{\prime \prime}\right)-\beta_{2}\right| \leftrightarrow\left|\gamma_{2}\right|>\left|\delta_{2}\right| .
\end{aligned}
$$

We refer to this last condition as the weak independence requirement, i.e. cognitive skills vary

\footnotetext{
${ }^{3} \mathrm{~A}$ simple proof can be found in Appendix 15.
} 
less with education and non-cognitive skills once Fraction Answered is controlled for.

\subsection{Test procedure}

We will test the validity of the proxy Fraction Answered for two different data applications (hourly wages, educational attainment) and two different omitted variables (cognitive skills, noncognitive skills). We can do so because we have reasonably accurate measures of both cognitive skills and non-cognitive skills available that are derived from a different data collection process than the data collection process used to construct the proxy variable (See Section 3).

The following three-step testing procedure contains a test for each of the three assumptions (strength, irrelevance, and weak independence) outlined above. We illustrate below the test procedure for hourly wages under the assumption that cognitive skills are unobserved, while education, cognitive skills, and Fraction Answered are observed. The same derivations hold if noncognitive skills are unobserved, while cognitive skills are observed, or if the outcome variable is educational attainment.

\section{Step 1: Strength}

To test assumption (1), we estimate a variant of Eq. (4) that includes Fraction Answered as main control variable, and adds subsequently blocks of control variables $\left(X_{i}^{\prime}\right)$ such as sex, age, educational qualification, ethnicity, and non-cognitive skills.

$$
C S_{i}=\alpha_{0}+\alpha_{1} F A_{i}+X_{i}^{\prime} \theta+\zeta_{i}
$$

We test the null hypothesis $H_{0}: \alpha_{1}=0$ against the two-sided alternative $H_{a}: \alpha_{1} \neq 0$. 
For Fraction Answered to be a strong proxy for cognitive skills, the null hypothesis needs to be unambiguously rejected even when adding the full set of control variables. There is no standard rule-of-thumb in the proxy-variable literature to judge whether the proxy variable is weak. We therefore report the correlation coefficient on Fraction Answered, its contribution to the explained variation in the respective skill measure, and the F-statistic that refers to the above outlined null hypothesis.

\section{Step 2: Irrelevance}

To test assumption (2), we re-estimate Eq. (3) by including our observed measure of cognitive skills:

$$
Y_{i}=\beta_{0}^{\prime \prime \prime}+\beta_{1}{ }^{\prime \prime \prime} \mathrm{EDU}_{\mathrm{i}}+\beta_{2}{ }^{\prime \prime \prime} \mathrm{NCS}_{\mathrm{i}}+\beta_{3}{ }^{\prime \prime \prime} \mathrm{FA}_{\mathrm{i}}+\beta_{4}{ }^{\prime \prime \prime} \mathrm{CS}_{\mathrm{i}}+\mathrm{u}_{\mathrm{i}}{ }^{\prime \prime \prime}
$$

For Fraction Answered to be a valid proxy variable, the estimated coefficient on Fraction Answered in Eq. (16) should converge towards zero. We test the null hypothesis $H_{0}: \beta_{3}{ }^{\prime \prime \prime}=0$ against the two-sided alternative $\mathrm{H}_{\mathrm{a}}: \beta_{3}{ }^{\prime \prime \prime} \neq 0$. For the proxy variable to pass this requirement, the null hypothesis must not be rejected. ${ }^{4}$

\section{Step 3: Weak independence}

\footnotetext{
${ }^{4}$ It is possible, that $F A_{i}$ is correlated with $u_{i}{ }^{\prime \prime \prime}$, hence has an independent effect on $Y_{i}$ and the coefficient may be biased. We argue that this is unlikely to be a problem in our case as we find that $\beta_{3}{ }^{\prime \prime \prime}$ is zero. Anything that would bias $\beta_{3}^{\prime \prime \prime}$ towards zero would have to be negatively related to $Y_{i}$ and positively related to $F A_{i}$. There are not many things one can think of that may fulfill these specific requirements as in general anything positively related to Fraction Answered would also be positively related to wages. The only possibility are opportunity costs which would reduce the number of questions answered but would be positively related to wages. However, we can show that all variables associated with opportunity costs (such as ability) are consistently positively associated with Fraction Answered. Hence, we conclude that it is unlikely that there is an independent effect of Fraction Answered on wages that biases the coefficients.
} 
To test assumption (3), we estimate both short (Eq. (12)) and long regressions (Eq. (4)), and then test whether the difference in the absolute value of coefficients between the short and long regression is greater than zero. For each pair of coefficient comparisons we have $H_{0}:\left|\gamma_{j}\right|-\left|\delta_{j}\right|=0(j=1$ for education and $j=2$ for non-cognitive skills) against the one-sided alternative $H_{a}:\left|\gamma_{j}\right|-\left|\delta_{j}\right|>0$. If we reject the null hypothesis, then the imperfect-proxy bias will be smaller than the omittedvariable bias.

\section{Data}

\subsection{Household, Income and Labour Dynamics in Australia Survey}

We use data from the Household, Income and Labour Dynamics in Australia (HILDA) Survey which is a nationally representative household panel study conducted yearly since 2001. All adult household members (aged 15 years and above) answer the continuing or new-person questionnaire which is conducted by an interviewer. In addition, each member is asked to fill out a self-completion questionnaire (SCQ) without the help of the interviewer. The completed SCQ is then either collected on the same day or at a later date by the interviewer, or returned by mail. Annually, approximately 13,000 individuals are interviewed since 2001. A top-up sample increased the respondent number to around 17,500 since 2011.

HILDA's unique data-collection feature of complementary self-completion and interviewerassisted surveys and its longitudinal nature allow us to separate the sources from which we construct measures of cognitive and non-cognitive skills and item non-response. Therefore, the proxy variable is not affected by non-response on the cognitive or non-cognitive skills. We use data from wave 12 (2012) when measures of cognitive skills (memory, coding speed, and language 
ability) were collected as part of the interviewer-assisted survey. As in 2012 no measures of noncognitive skills were collected, we attach to wave 12 information on the Big-Five personality traits (extraversion, agreeableness, conscientiousness, emotional stability, openness to experience) and locus of control that was collected in SCQs in previous waves (waves 3, 4, 5, 7, and 9). Our proxy Fraction Answered is calculated from the 2012 SCQ. ${ }^{5}$

About $90 \%(15,380)$ of the respondents returned the 2012 SCQ. Conditioning on non-missing observations in the cognitive and non-cognitive skills, we obtain a sample of 10,977 individuals. This sample further drops to 7,954 individuals when conditioning on non-missing observations in all control variables, and to 4,103 individuals when conditioning on non-missing observations in hourly wages.

\subsection{Fraction Answered}

To construct the number of non-response in the self-completion questionnaire (SCQ), we make use of the missing value conventions in the HILDA dataset, and count "Don't know" and "Refused"/"not answered" as non-response. ${ }^{6}$ Only questions that appear in the questionnaire are used; derived variables are therefore excluded when constructing the non-response count. Whenever a question generates more than one variable in the dataset, the number of non-responses needs to be adjusted to avoid double counting. ${ }^{7}$

We discard all individuals who did not return the SCQ. The non-response fraction is calcu-

\footnotetext{
${ }^{5}$ We considered calculating a non-response proxy also from the interviewer-assisted continuing/new-person questionnaire, but there was too little variation in non-response to make it a useful proxy variable.

${ }^{6}$ In a robustness check we excluded the response "Don't Know" from non-response. Our conclusions remain unaffected.

${ }^{7}$ For example, the question on height allows a response in different units, so that two variables are provided in HILDA for the question. There are a range of questions on life events, and for each the respondent was asked whether it happened in the last 12 months, and if so to indicate whether it happened 0 to 3,4 to 6,7 to 9 , or 10 to 12 months ago (resulting in six separate variables for each event although there are essentially only two questions on each event - "Did it happen?" and if so "How many months ago?").
} 
lated for each individual as the ratio of the number of unanswered questions to the total number of questions that the respondent was asked. The denominator varies across individuals as some people are asked more questions than others depending on whether certain questions apply to the individual's personal situation. Figure 1(a) shows that the total range in applicable questions varies from 181 to 258 questions, and there is heaping of required responses around every additional eleven required questions. The most frequent number of required questions are $207(8 \%)$, $235(12 \%)$, and $256(10 \%)$. Figure 1(b) shows that the total number of unanswered items in wave 12 varies between $0(31 \%)$ and 200 . About $90 \%$ of the sample failed to respond to up to 10 items. About $1 \%$ of the sample refused to answer 50 or more questions. A 1 standard-deviation (SD) increase in item non-response is associated with 10.5 additional questions not responded to in the SCQ.

\section{[Insert Figures 1(a) and 1(b) here]}

Figure 2 describes the distribution of the non-response rate separately for male and female respondents for non-response rates of $10 \%$ or less. The distribution is highly right-skewed, and differs across the sexes (p-value of Kolmogorov-Smirnov test of equal distribution is 0.005), although we cannot find dominance of one distribution over the other.

\section{[Insert Figure 2 here]}

\subsection{Cognitive skills}

An individual's cognitive skills are measured by three tests conducted in Wave 12 (2012): (1) the 'Backward digits span' test (BDS), (2) a 25-item version of the 'National American Reading Test' 
(NART) and (3) the 'Symbol-digit modalities' test (SDM). Participation rates were high (>93\% in each test). Details on the tests and how they were conducted are provided in Wooden (2013).

The BDS measures working memory span and is a traditional sub-component of intelligence tests. The interviewer reads out a string of digits which the respondent has to repeat in reverse order. NART is a short version of the National Adult Reading Test that measures pre-morbid intelligence. Respondents are shown 25 irregularly spelled words which they have to read out loud and pronounce correctly. SDM was originally developed to detect cerebral dysfunction but is now a recognized test for divided attention, visual scanning and motor speed. Respondents have to match symbols to numbers according to a printed key that is given to them.

We also construct a combined measure of cognitive skills by conducting a factor analysis on all three measures and predicting the first factor. All cognitive ability measures are standardized to mean 0 and standard deviation 1.

\subsection{Non-cognitive skills}

To construct measures of non-cognitive skills, we use data on the Big-Five personality traits and locus of control. In waves 5 and 9, HILDA collected an inventory of the Big-Five personality traits based on Saucier (1994). It consists of 30 of Saucier's original 40 items, and six additional items were added to the survey. Ultimately, 28 of these 36 items are used to construct five aggregate scores of personality. The five dimensions-extraversion, agreeableness, conscientiousness, emotional stability, and openness to experience-represent personality at the broadest level of abstraction. Each trait is scored from 1 to 7 , with a high score indicating that the personality trait describes the individual very well. The distribution of each trait is left-skewed, which means that a larger proportion of the sample agrees with the statements about their personality underlying 
each trait (See Cobb-Clark and Schurer, 2012, for a detailed description).

A measure of locus of control is derived from seven available items from the Psychological Coping Resources component of the Mastery Module developed by Pearlin and Schooler (1978), which were collected in waves 3,4 , and 7 . Mastery refers to beliefs about the extent to which life's outcomes are under one's own control. Specifically, respondents were asked the extent to which they agree with each of the seven statements described in Table 7 in the Online Appendix. Possible responses range from 1 (strongly disagree) to 7 (strongly agree). We construct a continuous measure of internal locus of control using factor analysis (See Cobb-Clark and Schurer, 2013; Cobb-Clark et al., 2014, for a description).

To minimize measurement error in the measures of non-cognitive skills, we follow CobbClark et al. (2014) by averaging the scores for each of the Big-Five personality traits from 2005 and 2009, and the scores for locus of control from 2003, 2004, and 2007. All personality variables are standardized to mean 0 and standard deviation 1.

\subsection{Other variables}

When assessing the association between cognitive or non-cognitive skills and Fraction Answered, we also control for the respondent's gender, age, education and ethnicity as we would like to see the associations net of these effects. We follow Leigh and Ryan (2008) and Li and Powdthavee (2014) to construct a continuous years of education measure from categorical variables that indicate the highest completed level of education. ${ }^{8}$

\footnotetext{
${ }^{8}$ Someone who completed a Masters or Doctoral degree is assigned 17 years of education; Graduate diploma or certificate is assigned 16 years; Bachelor or honours is assigned 15 years; Advanced diploma or diploma or just finishing year 12 is assigned 12 years; Finishing a Certificate III/IV is also assigned 12 years; Finishing Year 11 is assigned 11 years; Minimum schooling is assigned 9 years; and dropping out of school before Year 9 is assigned 8 years.
} 
We also investigate the association between the interviewer's assessment of the interviewee's understanding of the questions, another variable derived from the survey's paradata, and Fraction Answered to understand pathways through which item non-response and cognitive/noncognitive skills are related. The interviewer judges the level of understanding on a five-point scale where 1 represents "very poor" and 5 "excellent". To make the strength of the associations comparable, we standardize this variable also to mean 0 and standard deviation 1.

There is more paradata information available in our data source which could be exploited as alternative proxies for cognitive or non-cognitive skills. These are, for instance, whether the individual failed to return a SCQ in 2012 (around 10\% of the sample, or 5\% of our sample that includes individuals who previously returned a SCQ), the minutes an individual spent on completing the person-specific or the household-specific questionnaires, or the number of days that elapsed between the receipt and the completion of the SCQ. In an extension to the main analysis we evaluate the suitability of these measures as proxy variables relative to Fraction Answered.

In the wage equations, we additionally account for the type of employment with a binary indicator of whether the respondent is a casual worker. As a measure for wages we use information on the respondent's log hourly wages that are constructed from gross annual salaries and wages and annual hours worked. All variables used in the subsequent analysis are described (before standardization) in Table 7 in the Online Appendix.

\section{Estimation results}

In the subsequent sections we test whether Fraction Answered in a self-completion questionnaire is a valid proxy for either cognitive or non-cognitive skills. We test the validity of this proxy variable in the context of wage and educational-attainment regression models. To test the validity, 
we follow the three-step test procedure outlined in Section 2.2. First, we test whether the correlation between Fraction Answered and individual measures of cognitive/non-cognitive skills is statistically and economically meaningful, even when controlling for a large set of confounding factors. This first step will help us to identify the particular skills with which Fraction Answered correlates the strongest (assumption (1)).

Then we move on to estimate standard wage and educational-attainment regression models that include either Fraction Answered, or both cognitive/non-cognitive skills. From these regression models we can directly test assumptions (2). The proxy variable must be redundant in the wage or educational-attainment regression when both the proxy, Fraction Answered, and the unobserved variable, either cognitive or non-cognitive skills, are included (assumption (2)). By regressing the 'unobserved' variable (e.g. cognitive skills) on both the proxy variable and the control variables used in the wage or educational-attainment regressions, we are able to test assumption (3). If the control variables of the wage or education-outcome equations are partially correlated in this long regression with the omitted variable, then the proxy-variable approach will yield biased and inconsistent estimates. However, if the partial correlation between omitted variable and the control variables becomes smaller in magnitude in the long relative to the short regression, the bias introduced by the imperfect proxy is smaller than the bias of omitting the proxied variable (Wooldridge, 2010, p.67-72).

\subsection{Correlation between Fraction Answered and skills}

In this section we test whether Fraction Answered is a strong proxy (assumption (1)) for cognitive or non-cognitive skills. Model (1) in Table 1 reports the bivariate correlation coefficients between Fraction Answered and each measure of cognitive and non-cognitive skills, and the contribution 
of Fraction Answered to the explained variation in each specific skill. In models (2)-(4) we report the multivariate correlation coefficients between the same variables but we subsequently add control variables such as sex, age, education, and ethnicity. In model (5) we add cognitive skills as control variables into the non-cognitive skill equations and non-cognitive skills into the cognitive skill equations. The results in each row in Table 1 stem from separate regression models that differ only by their outcome variables. All outcome variables and Fraction Answered are standardized to mean 0 and standard deviation 1.

\section{[Insert Table 1 here]}

The correlation coefficients are the strongest between measures of cognitive skills and Fraction Answered, with a maximum association obtained for the Symbol-Digits-Modalities test (SDM). Fraction Answered explains 4.5\% of the variation in the SDM score. A 1 SD increase in Fraction Answered, which corresponds to an additional 10.5 questions answered on the SCQ, is associated with a 0.212 SD increase in the SDM score. Fraction Answered is also associated with higher scores on the National Adult Reading (NART) (0.129 SD) and the Backward-Digit-Span (BDS) test scores $(0.114 \mathrm{SD})$, and it explains $1.7 \%$ and $1.3 \%$ of the variation in NART and BDS, respectively. All correlations are highly statistically significant, with F-statistics in the order of magnitude of 113 (BDS), 394 (SDM), and 145 (NART).

When controlling for sex, age, education, ethnicity and non-cognitive skills, the associations are reduced by $30-45 \%$, but they are still sizable and statistically significant (F-statistics are for BDS: 57, SDM: 203, NART: 100). Fraction Answered passes unambiguously the minimum requirement to be a valid proxy for cognitive ability. ${ }^{9}$

\footnotetext{
${ }^{9}$ The tests are passed equally strongly when using the first predicted value of all three cognitive ability measures. The correlation coefficient with Fraction Answered is 0.200 SD, Fraction Answered explains $4.1 \%$ of its variation, and the F-statistics in model (1) and (5) are 364 and 191, respectively.
} 
Fraction Answered also correlates, although less strongly, with some of the non-cognitive skills. In order of magnitudes, the strongest correlation coefficients are obtained for openness to experience (0.09 SD), locus of control (0.07 SD), agreeableness (0.05 SD), and conscientiousness (0.03 SD). In some cases, the correlation coefficient becomes stronger when controlling for the full set of control variables (model (5)) as in the case of conscientiousness (0.04 SD) and agreeableness (0.06 SD). For openness to experience and locus of control, the correlation coefficient is reduced by two-thirds when controlling for cognitive skills. These correlation coefficients are all significant at the 1 percent level, but their F-statistics vary substantially. It is only for agreeableness, openness to experience, and locus of control that the F-statistic is large, between 20 and 70 in both models (1) and (5). ${ }^{10}$ Fraction Answered is not related to extraversion and emotional stability. In contrast to cognitive skills, Fraction Answered explains less than $1 \%$ of the variation in each of the considered non-cognitive skills.

To ascertain that the association between Fraction Answered and cognitive skills is not due to other unobserved factors (e.g. opportunity costs), but due to a better understanding of the questions, we also report the correlations between Fraction Answered and other paradata available in our dataset (see lower panel). We find a strong correlation between the interviewer's assessment of the respondent's understanding of the questions. A 1 SD increase in the Fraction Answered is associated with a 0.134 SD increase in the interviewer's rating of the subject's understanding of the questions, which drops to 0.068 SD when controlling for both cognitive and non-cognitive skills. The F-statistics in model (1) and (5) are large (155, 101), and Fraction Answered explains almost $2 \%$ of the variation in the interviewer's rating. Fraction Answered is also

\footnotetext{
${ }^{10}$ The F-statistics in model (1) and (5) are for agreeableness: 22 and 41; for openness to experience: 669 and 20; for locus of control: 55 and 21; and for conscientiousness: 6 and 21, respectively.
} 
positively correlated with the total time taken to answer the household questionnaire. A onestandard-deviation increase in Fraction Answered is associated with a 0.034 standard deviation increase in the minutes spent on completing the household questionnaire, however, the association is entirely explained by observable factors. ${ }^{11}$

That Fraction Answered is likely to capture cognitive ability can be observed in Figure 3(a), in which we plot the relationship between cognitive ability and age and compare it to the relationship between Fraction Answered and age. Both figures are based on non-parametric kernel regression methods to allow for non-linearities (See e.g. Wand and Jones, 1995). Cognitive ability, which is here measured as the first predicted factor, strongly declines from age 40 onward, and declines even more strongly from age 65 onward. Fraction Answered also starts declining from about age 40, but at a flatter profile, but the age gradient steepens substantially from age 65 onward. Figure 3(b) clarifies that the similarities in the age gradients of both Fraction Answered and cognitive ability are mainly driven by the Backward Digit Span.

\section{[Insert Figures 3(a) and 3(a) here]}

In a further robustness check, we re-estimate the bivariate relationships from model (1) also using a non-parametric kernel regression method to allow for non-linearities between Fraction Answered and skills. The estimated results are plotted in Figure 4, where on the horizontal and vertical axes we report the skill measures and the distribution of Fraction Answered, respectively.

\section{[Insert Figures 4 here]}

We conclude that the relationship between Fraction Answered and cognitive skills is approximately linear over a wide range of values for both the BDS and NART. Some non-linearities

\footnotetext{
${ }^{11} \mathrm{We}$ could not find any association between the time spent on completing the personal questionnaire or the days elapsed between receiving and completing the SCQ. Results provided upon request.
} 
emerge for the SDM test, openness to experience and locus of control mainly in the left tail of the skill distribution $(<-2 \mathrm{SD}$ away from the mean). For most observations in the data that lie within the range of -2 to $2 \mathrm{SD}$ around the mean, the relationship is approximately linear. We no longer find a discernable relationship between Fraction Answered and agreeableness or conscientiousness. The strong non-linearities emerging in extraversion and emotional stability are deceptive; they oscillate around the zero mean of Fraction Answered, given their wide confidence intervals.

We infer from these results that ignoring the possible non-linearities between cognitive/noncognitive skills and Fraction Answered is unlikely to weaken the strength (assumption (1)) of Fraction Answered as a proxy for cognitive skills, openness to experience, and locus of control.

\subsection{Alternative proxies for cognitive and non-cognitive skills}

Given the specific protocol that governs the data collection process of the HILDA Survey, we are able to derive alternative proxy variables such as 'Interviewer rating', 'No SCQ returned in 2012', 'Minutes spent on completing the unique personal or household questionnaires', and 'Days elapsed to complete SCQ since receipt'. Each of these variables could be good proxies for e.g. conscientiousness and cognitive ability. Individuals with higher cognitive abilities may be able to complete the surveys faster by being able to read, comprehend, and respond to the questions. However, less time spent on the survey could also be the result of careless behavior. Very conscientious individuals may take more time to respond to the questions by carefully reading the questions and discussing with the interviewer which information is required for a valid response. Individuals who do not return the SCQ may either be very careless (low on conscientiousness), or uncooperative (low on agreeableness). On the contrary, they may not return the SCQ because 
of very high opportunity costs.

In this section we identify and discuss the strength of the correlation between these alternative proxies, relative to Fraction Answered, and both cognitive and non-cognitive skills. Table 8 in the Online Appendix displays a correlation matrix for all proxy variables, including Fraction Answered, and all measures of cognitive and non-cognitive skills. All measures are standardized so that a one-unit change reflects a move from the bottom to the top of the distribution to make the unit of analysis comparable to the binary indicator 'No SCQ'. We find that 'Minutes to complete the unique person questionnaire' (or to complete the household questionnaire) is most strongly positively correlated with openness to experience (0.09) and cognitive ability (0.06). 'No SCQ in 2012 ' is most strongly and negatively correlated with cognitive ability (0.06) and conscientiousness (0.08). Interviewer rating is strongly correlated with cognitive ability (0.282), openness to experience (0.09), and locus of control (0.16). No significant correlations emerge between 'Days elapsed' and any of the skill measures.

Since many of these alternative proxy variables derived from paradata also fulfill requirement (1), we test their validity as proxy in the subsequent analysis. This will allow us to evaluate the relative strength of Fraction Answered as proxy variable for unobserved skills. The strongest contender will be interviewer rating of the respondent's understanding of the questions as it correlates more strongly with cognitive ability than Fraction Answered (0.28 versus 0.21$)$.

\subsection{Application 1: Hourly wages}

Having shown that Fraction Answered correlates strongly with all cognitive and some noncognitive skill measures, we now test whether Fraction Answered passes assumptions (2) and (3) in a standard wage regression. In Table 2 we report the multivariate relationships between 
$\log$ hourly wages ${ }^{12}$ and Fraction Answered. All models are estimated with OLS and control for gender, age, age squared, age cubed, a measure for casual worker and educational attainment on a sample of 3,999 working individuals.

In model (1) we report the estimated coefficients obtained from a model that includes the basic set of control variables plus either Fraction Answered or one of the individual cognitive or non-cognitive skill measures. To test assumption (2), we include into the model with the basic set of control variables Fraction Answered, cognitive skills, and non-cognitive skills (model (2)). To pass assumption (2) the coefficient on Fraction Answered has to become zero in both statistical and economic terms, as we move from model (1) to (2).

\section{[Insert Table 2 here]}

Fraction Answered is strongly correlated with hourly wages. A 1 SD increase in the Fraction Answered is associated with a $4.2 \%$ increase in hourly wages, which is (almost) identical to the effect of an equivalent increase in the BDS test score (5.7\%), conscientiousness (6.3\%), and emotional stability (3.6\%) on wages. The relationships with wages for the SDM and NART test scores tend to be stronger $(12 \%)$.

Overall, the coefficient on Fraction Answered is no longer statistically significant at the 5\% level or better when controlling for both cognitive and non-cognitive skills as is displayed in model (2) of Table 2, and therefore passes assumption (2). The estimated coefficient on Fraction Answered drops significantly by $45 \%$ from 0.042 to 0.023 (p-value $<0.001$ ).

However, the estimation results from model (2) do not allow us to evaluate whether Fraction Answered is a valid proxy for cognitive or non-cognitive skills. We therefore estimate two further

\footnotetext{
${ }^{12}$ The same results hold when using gross annual earnings. Robustness checks are provided upon request.
} 
models, in which we include only non-cognitive (model (3)) or cognitive skills (model (4)) in addition to Fraction Answered. ${ }^{13}$

When controlling for both Fraction Answered and non-cognitive skills (model (3)), the effect of Fraction Answered on wages does not drop (from 0.042 to 0.039 ) significantly, and is still statistically significant at the $1 \%$ level. We may have over-estimated this coefficient, because we have omitted cognitive skills, which positively correlate with Fraction Answered. Therefore, we cannot say whether Fraction Answered passes assumption (2) if proxying non-cognitive skills with certainty.

In stark contrast, when controlling for Fraction Answered and cognitive skills in model (4), the estimated coefficient on Fraction Answered decreases significantly by $40 \%$ from 0.042 to 0.025 (p-value $<0.001)$ and is no longer statistically significant at the $5 \%$ level or better. Since we are likely to overestimate the coefficient on Fraction Answered due to omitting non-cognitive skills, with which Fraction Answered is positively correlated, we have certainty that Fraction Answered passes assumption (2) when used as a proxy for cognitive skills.

Thus, from here onward we restrict our testing procedure for assumption (3) to Fraction Answered as a valid proxy for cognitive skills. The test results are presented in Table 3. In model (1) we present the estimated coefficients from the short regression of cognitive skills (first predicted factor standardized to mean 0 , standard deviation 1 ) on the control variables used in the wage regression, while in model (2) we present the estimated coefficients from the long regression that

\footnotetext{
${ }^{13}$ Technically speaking, both model (3) and (4) yield biased estimates on the coefficient of Fraction Answered, because we omit either cognitive or non-cognitive skills, of which we know correlate strongly with Fraction Answered. However, we know that Fraction Answered positively correlates with all cognitive and non-cognitive skills, and so, at worst, we are likely to over-estimate the coefficient on Fraction Answered. To pass assumption (2) the coefficient on Fraction Answered requires to be zero. To commit a Type II error, that is erroneously accepting a null hypothesis, would happen in our case only if Fraction Answered negatively correlates with cognitive or non-cognitive skills. In this case, the coefficient on Fraction Answered would be downward biased.
} 
includes also the proxy variable Fraction Answered. In column 3 we report the estimated differences between the absolute values of coefficients of models (1) and (2). Column 4 reports the relevant p-value of a test statistic which tests under the null that the coefficients in model (1) are the same as the coefficients in model (2), against the alternative that the coefficients in model (1) are larger (in absolute values). The proxy-variable approach is preferable to omitting the unobserved variable if at least some of the coefficients on the potentially endogenous variables decrease in a statistically meaningful way, while no others increase in magnitude.

\section{[Insert Table 3 here]}

We consider the change in magnitude of the estimated coefficients for both years of education and the non-cognitive skill variables that were used as predictors in the hourly-wage equation. The p-values from column 4 in Table 3 show that we reject the null hypothesis against the alternative in the case of years of education, openness to experience, and locus of control. Fraction Answered therefore passes the third requirement to be a valid proxy for cognitive skills.

Although not a perfect proxy, its bias will be smaller than the bias caused by omitting cognitive skills from the hourly wage regression. In our specific sample, the bias reduction lies between $3 \%$ for the estimated coefficient on years of education and almost $11 \%$ for the estimated coefficient on internal locus of control (See column 5 of Table 3). We conclude that Fraction Answered predominantly captures the coding-speed element of cognitive skills. Approximately $36 \%(0.042 / 0.118$ in Table 2, model (1)) of the effect of the Symbol-Digits-Modalities test is explained by Fraction Answered. 


\subsection{Application 2: Years of education}

In this section we test whether Fraction Answered passes assumption (2) and (3) in the context of educational-attainment models, following the same procedural steps as for hourly wages. We start out with a baseline OLS model in which we regress years of education on a dummy variable for being male and a quadratic polynomial of age $(\mathrm{N}=7,954)$. Estimation results for testing assumption (2) are reported in Table 4.

In model (1) we report the estimated coefficients obtained from a model that includes the basic set of control variables plus either Fraction Answered or one of the individual cognitive or non-cognitive skill measures. To test assumption (2), we include into the model with the basic set of control variables Fraction Answered, cognitive skills, and non-cognitive skills (model (2)). To pass assumption (2) the coefficient on Fraction Answered has to become zero in both statistical and economic terms, as we move from model (1) to (2).

\section{[Insert Table 4 here]}

Fraction Answered strongly correlates with years of education. A one-standard deviation increase in Fraction Answered is associated with a 0.1 standard-deviation increase in years of education (model (1)). The estimated coefficient on Fraction Answered is no longer statistically significant at the $1 \%$ level when controlling for both cognitive and non-cognitive skills when moving from model (1) to model (2) in Table 4. The estimated coefficient drops significantly by $76 \%$ from 0.094 SD to 0.023 SD (p-value $<0.001)$

Again, model (2) does not allow us to evaluate whether Fraction Answered is a valid proxy for cognitive or non-cognitive skills. We therefore estimate two further models, in which we include, apart from the baseline control variables and Fraction Answered, either non-cognitive 
skills (model (3)) or cognitive skills (model (4)). Note again, in both models (3) and (4) we are likely to overestimate the coefficient on Fraction Answered due to omitting either cognitive or non-cognitive skills. When controlling for both Fraction Answered and non-cognitive skills in model (3), the effect of Fraction Answered on years of education, although decreasing slightly, is still highly statistically significant. In stark contrast, when moving from model (1) to model (4), which controls for Fraction Answered and cognitive skills, the estimated coefficient on Fraction Answered decreases significantly by $71 \%$ from 0.094 SD to 0.027 SD (p-value $<0.001$ ). Although still statistically significant at the $1 \%$ level, Fraction Answered is likely to pass assumption (2) when used as a proxy for cognitive skills, because of its dramatic drop in magnitude. We therefore continue our test procedure only for Fraction Answered to be used as proxy for cognitive skills.

Column 3 in Table 5 reports the estimated difference in the absolute value of coefficients of the endogenous non-cognitive skill variables between the short (model (1)) and the long regression (model (2)). The results indicate that the estimated coefficients drop significantly in magnitude for extraversion, openness to experience, and locus of control, while the difference is insignificant for agreeableness, conscientiousness and emotional stability.

\section{[Insert Table 5 here]}

Again, although not a perfect proxy, its bias will be smaller than the bias caused by omitting cognitive skills from the years-of-education regression. In our specific sample, the bias reduction in the estimated coefficients on extraversion, internal locus of control, and openness to experience are in the order of magnitude of 7.2\%, 4.7\%, and 2.6\%, respectively (See column 5 of Table 5). These findings emphasize that our measure of Fraction Answered predominantly captures educationrelated variation in cognitive skills. Approximately $31 \%(0.094 / 0.304$ in Table 4 , model 1$)$ of the 
effect of the Symbol-Digits-Modalities test is explained by Fraction Answered.

\subsection{Relative performance of Fraction Answered}

We have shown so far that Fraction Answered passes all three requirements to be a valid proxy for cognitive skills in both wage and educational-attainment regressions, and that its application reduces the omitted-variable bias in some coefficients by up to $11 \%$. We have also shown that alternative proxy variables also derived from paradata could be powerful solutions to the omittedvariable problem. In this section we evaluate the relative performance of Fraction Answered against these alternatives.

Table 6 summarizes the validity test results of all four proxy variables (Fraction Answered, Interviewer Rating, No matched SCQ (in 2012), and Time take for completing the household questionnaire (HHQ)). ${ }^{14}$ For brevity, we consider the validity of these alternatives as proxies for unobserved cognitive ability in the context of a wage-regression model.

\section{[Insert Table 6 here]}

All four proxy variables unambiguously pass assumption (1). All of them correlate significantly with cognitive skills, although the strongest correlation coefficients are obtained for Fraction Answered and Interviewer Rating. However, Interviewer Rating does not pass assumption (2), nor does Time taken to complete the HHQ. The proxy variable 'No matched SCQ' technically passes assumption (2), but it does not correlate with hourly wages even when omitting cognitive and non-cognitive skills from the wage regression. It also does not pass assumption (3).

Finally, both Interviewer Ratings and Time spent to complete the HHQ pass assumption (3) and entail a reduction in the omitted variables for some variables. However, the bias-reduction

\footnotetext{
${ }^{14}$ Full estimation results are provided in the Online Appendix.
} 
in estimated coefficients on e.g. years of education, does not exceed the bias reduction obtained through Fraction Answered.

Therefore, we are able to show that Fraction Answered is the only proxy variable derived from paradata that unambiguously passes all three requirements to be a valid proxy variable for cognitive ability.

\section{Conclusions}

In this study, we develop a simple three-step procedure to test the validity of a proxy variable derived from paradata that can be applied to many settings and research questions. Following the procedural steps, we are able to show that item-non-response information obtained from an unassisted self-completion questionnaire is strongly correlated with highly-validated measures of cognitive skills, and to a lesser extent with measures of non-cognitive skills. Put to the test, Fraction Answered turns out to be a valid proxy for cognitive skills, but not for non-cognitive skills, in both wage and educational-attainment regressions. It also turns out to be the only proxy variable among several alternatives equally derived from paradata to fulfill all requirements of a valid proxy variable.

This conclusion has valuable implications for the modeling strategy of applied researchers. Although not perfect, we provide a simple solution to reduce omitted-variable biases in estimated coefficients on years of education or cognitive skills in the magnitude of 3 to $11 \%$ when cognitive ability is the omitted variable.

We find the strongest associations between Fraction Answered and the Symbol-Digit-Modalities test score, a measure of coding speed that exhibits a strong age-gradient, and the National Adult Reading Test score. Favoring Fraction Answered as a proxy for coding speed and language ability 
over openness to experience or locus of control is surprising, but this finding is corroborated by the interviewer's assessment about the respondent's understanding of the questions. Item nonresponse is largely driven by the subject's poor (cognitive) understanding of the questions, and not due to a personality-related unwillingness to complete all survey questions.

Our results may prove useful to researchers using data collected with unassisted self-completion questionnaires. The strong association between item non-response and cognitive ability points to the strong degree of self-selection of cognitively more able individuals to provide complete information. This selection may potentially bias the researcher's analysis when using most-affected questions from such self-completion questionnaires. Depending on the individual research question and variables used, the researcher may want to account for this self-selection. These results may also prove valuable to survey collectors who would like to boost their response rates. Survey collectors may need to rethink their survey design to allow people with lesser cognitive skills to understand and answer the questions.

\section{References}

Aigner DJ. 1974. Mse dominance of least squares with errors of observation. Fournal of Econometrics 2: 365-372.

Almlund M, Lee Duckworth A, Heckman JJ, Kautz T. 2011. Personality psychology and economics. In Eric A Hanushek SM, Woessmann L (eds), Handbook of the Economics of Education, volume 4. North-Holland, 1-181.

Beatty P, Herrmann DJ. 2002. To answer or not to answer: Decision processes related to survey 
item nonresponse. In Groves RM, Dillman DA, Eltinge JL, Little RJA (eds), Survey Nonresponse. New York: John Wiley and Sons, 71-86.

Behaghel L, Crepon B, Gurgand M, Le Barbanchon T. 2015. Please call again: Correcting nonresponse bias in treatment effect models. Review of Economics and Statistics Forthcoming.

Bollinger C. 2003. Measurement error in human capital and the black-white wage differential. Review of Economics and Statistics 85: 578-585.

Cobb-Clark DA, Kassenboehmer S, Schurer S. 2014. Healthy habits: What explains the connection between diet, exercise, and locus of control? Journal of Economic Behavior \& Organization 98: $1-28$.

Cobb-Clark DA, Schurer S. 2012. The stability of big-five personality traits. Economics Letters 115: $11-15$.

Cobb-Clark DA, Schurer S. 2013. Two economists' musings on the stability of locus of control. The Economic Journal 123: F358-F400.

Fletcher JJ, Schurer S. 2014. The effect of childhood health and mistreatment on adulthood personality: Evidence from siblings data. Unsubmitted manuscript, University of Sydney.

Fletcher JM. 2013. The effects of personality traits on adult labor market outcomes: Evidence from siblings. Journal of Economic Behavior \& Organization 89: 122-135.

Groves R, Couper M. 1998. Nonresponse in Household Interview Surveys. New York: Wiley.

Heffetz O, Rabin M. 2013. Conclusions regarding cross-group differences in happiness depend on difficulty of reaching respondents. American Economic Review 103. 
Kleinjans KJ, van Soest A. 2014. Rounding, focal point answers and nonresponse to subjective probability questions. Fournal of Applied Econometrics 29: 567-585.

Kreuter F. 2013. Improving Surveys with Paradata: Analytic Uses of Process Information. John Wiley \& Sons.

Leigh A, Ryan C. 2008. Estimating returns to education using different natural experiment techniques. Economics and Education Review 27: 2.

Li J, Powdthavee N. 2014. Does more education lead to better health habits? evidence from the school reforms in australia. Social Science \& Medicine Forthcoming.

Lundberg S. 2013. The college type: Personality and educational inequality. Fournal of Labor Economics 31: 421-441.

McCallum BT. 1972. Relative asymptotic bias from errors of omission and measurement. Econometrica 40: 757-758.

Neal DA, Johnson WR. 1996. The role of premarket factors in black-white wage differences. Journal of Political Economy 104: 869-895.

Pearlin LI, Schooler C. 1978. The structure of coping. Fournal of Health and Social Behavior 19: $2-21$.

Saucier G. 1994. Mini-markers: A brief version of Goldberg's unipolar Big-Five markers. fournal of Personality Assessment 63: 506-516.

Wai J. 2013. Investigating America's elite: Cognitive ability, education, and sex differences. Intelligence 41: 203-211. 
Wand MP, Jones M. 1995. Kernel smoothing. Monographs on Statistics and Applied Probability. London: Chapman and Hall.

Wickens MR. 1972. A note on the use of proxy variables. Econometrica 40: 759-760.

Wooden M. 2013. The measurement of cognitive ability in wave 12 of the hilda survey. HILDA Project Discussion Paper Series 1/13, Melbourne Institute of Applied Economic and Social Research.

Wooldridge JM. 2003. Introductory Econometrics - A modern Approach. Mason, OH: SoutherWestern.

Wooldridge JM. 2010. Econometric Analysis of Cross Sectiona And panel Data. The MIT Press. 


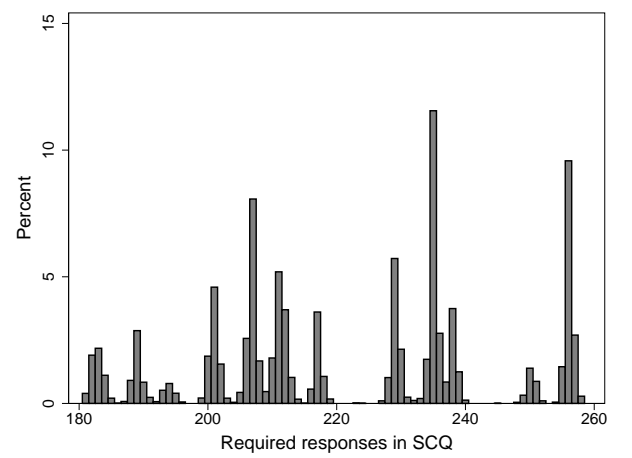

(a) Required responses

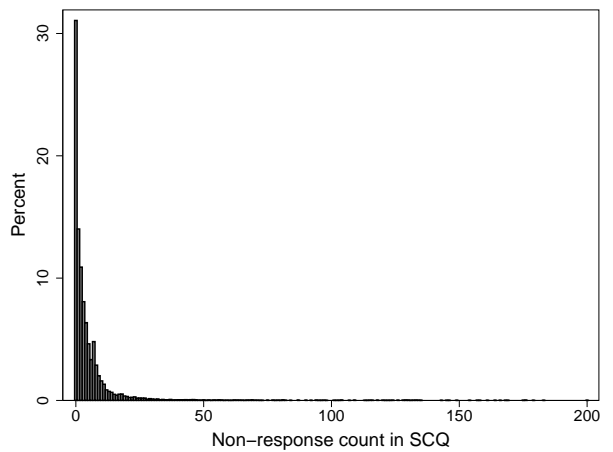

(b) Non-response

Figure 1: Distribution of required number of questions and of count of non-responded questions in SCQ (wave 12)

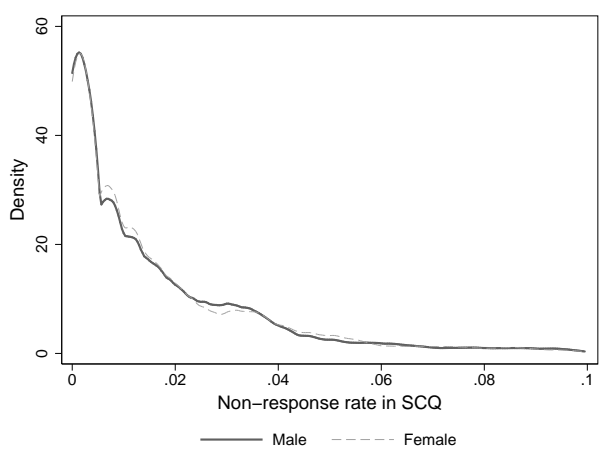

Figure 2: Distribution of non-response rate in SCQ (wave 12), by sex (p-value of KolmogorovSmirnov test of equal distribution: $\mathrm{p}=0.005$ ) 


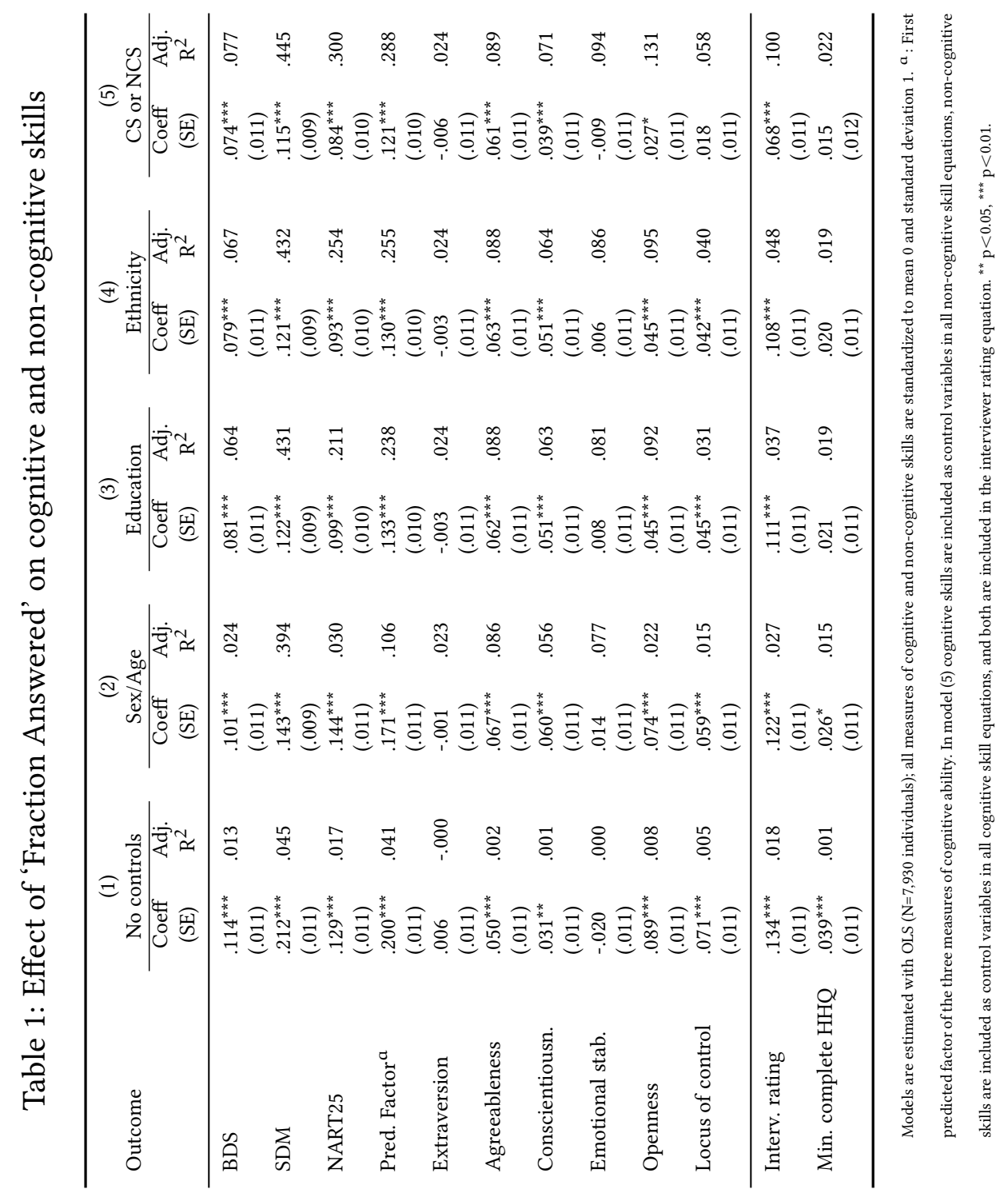




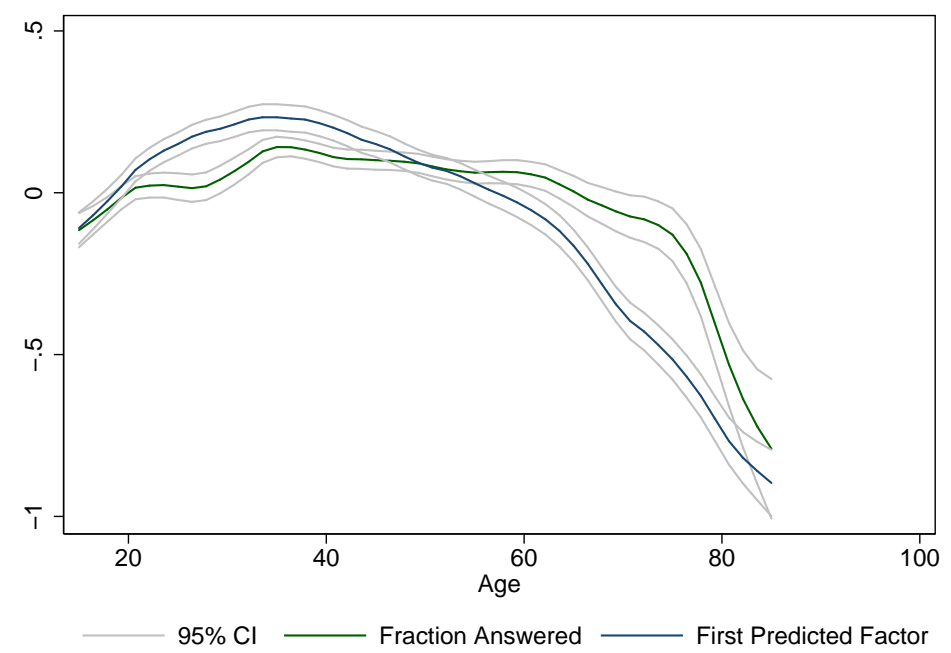

(a) First predicted factor

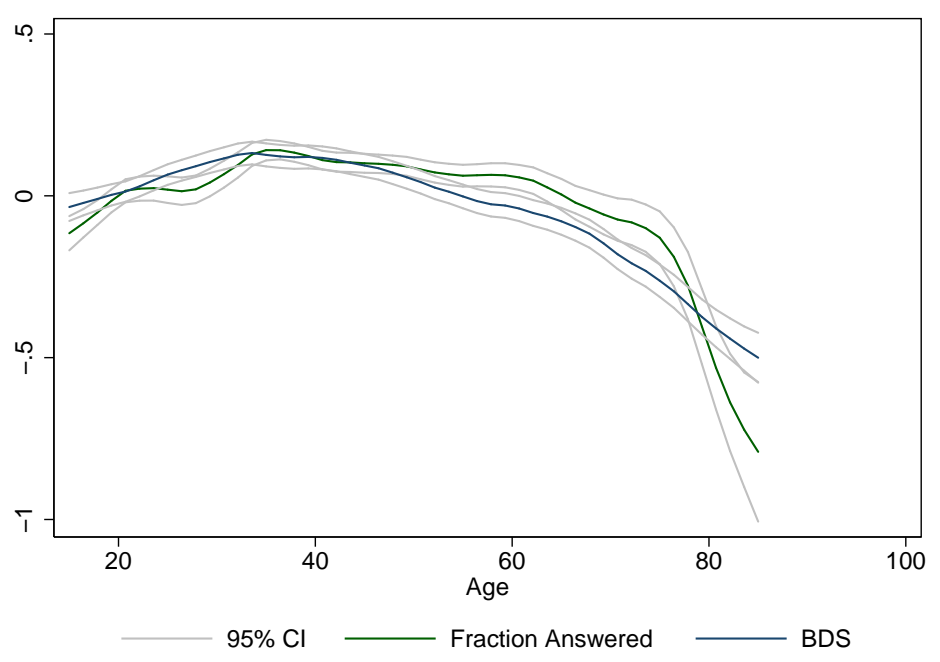

(b) Backward-Digit Span

Figure 3: Non-linearities in the relationship of Fraction Answered and Cognitive Ability with Age (15 to 85 only) (bivariate non-parametric kernel regression) 


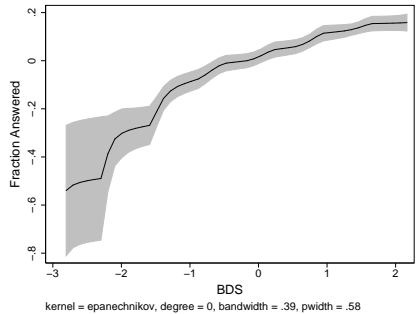

(a) BDS

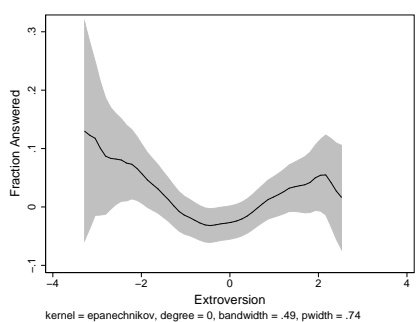

(d) Extraversion

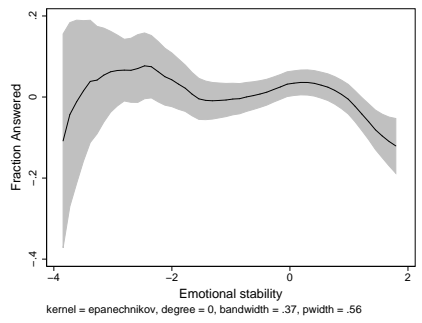

(g) Emotional stability

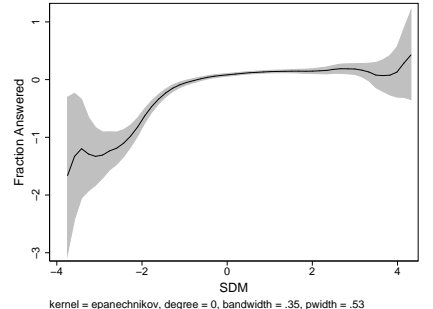

(b) SDM

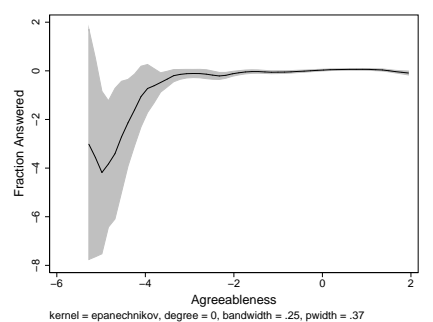

(e) Agreeableness

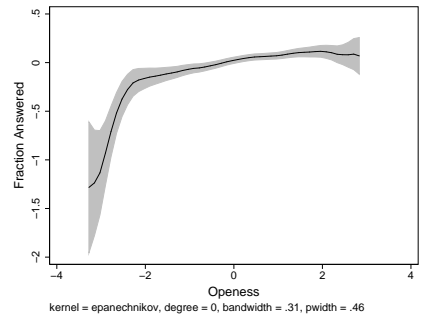

(h) Openness to experience

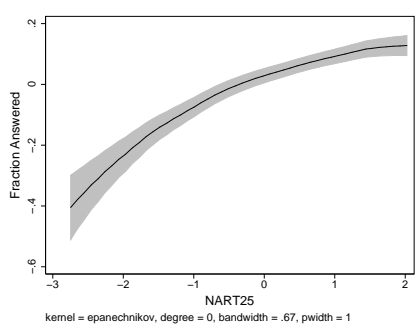

(c) NART 25

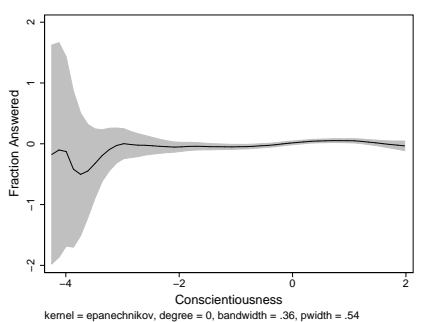

(f) Conscientiousness

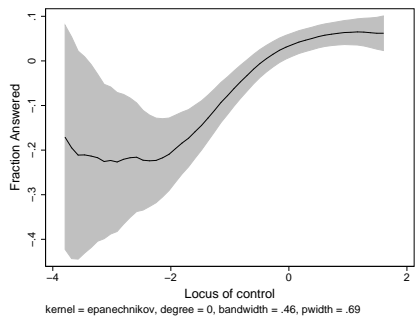

(i) Locus of control

Figure 4: Non-linearities in the relationship between cognitive or non-cognitive skills and Fraction Answered (bivariate non-parametric kernel regression) 
Table 2: Effect of Fraction Answered on log hourly wages

\begin{tabular}{|c|c|c|c|c|c|c|c|c|}
\hline \multirow[t]{5}{*}{ Variables } & \multirow{2}{*}{\multicolumn{2}{|c|}{$\begin{array}{c}\text { Incl. NCS/CS } \\
\text { indiv. }\end{array}$}} & \multicolumn{6}{|c|}{ Incl. FA jointly with NCS and/or CS } \\
\hline & & & NCS \& & $\mathrm{CS}$ & $\mathrm{NC}$ & & $\mathrm{C}$ & \\
\hline & \multicolumn{2}{|c|}{ Model (1) } & \multicolumn{2}{|c|}{ Model (2) } & \multicolumn{2}{|c|}{ Model (3) } & \multicolumn{2}{|c|}{ Model (4) } \\
\hline & Coeff & Adj. & Coeff & Adj. & Coeff & Adj. & Coeff & Adj. \\
\hline & (SE) & $\mathrm{R}^{2}$ & (SE) & $\mathrm{R}^{2}$ & (SE) & $\mathrm{R}^{2}$ & (SE) & $\mathrm{R}^{2}$ \\
\hline \multirow[t]{2}{*}{ Fraction Answered } & $.042^{* * *}$ & .259 & .023 & .284 & $.039^{* * *}$ & .268 & .025 & .277 \\
\hline & $(.014)$ & & $(.014)$ & & $(.014)$ & & $(.014)$ & \\
\hline \multirow[t]{2}{*}{ BDS } & $.057^{* * *}$ & .261 & .006 & & & & .008 & \\
\hline & $(.014)$ & & $(.015)$ & & & & $(.015)$ & \\
\hline \multirow[t]{2}{*}{ SDM } & $.124^{* * *}$ & .270 & $.093^{* * *}$ & & & & $.098^{* * *}$ & \\
\hline & $(.015)$ & & $(.016)$ & & & & $(.016)$ & \\
\hline \multirow[t]{2}{*}{ NART25 } & $.118^{* * *}$ & .269 & $.090^{* * *}$ & & & & $.089^{* * *}$ & \\
\hline & $(.015)$ & & $(.016)$ & & & & $(.016)$ & \\
\hline \multirow[t]{2}{*}{ Extraversion } & $.031^{* *}$ & .258 & .022 & & .014 & & & \\
\hline & $(.014)$ & & $(.014)$ & & $(.014)$ & & & \\
\hline \multirow[t]{2}{*}{ Agreeableness } & -.019 & .258 & $-.038^{* *}$ & & $-.049^{* * *}$ & & & \\
\hline & $(.014)$ & & $(.015)$ & & $(.015)$ & & & \\
\hline \multirow[t]{2}{*}{ Conscientiousness } & $.063^{* * *}$ & .261 & $.054^{* * *}$ & & $.052^{* * *}$ & & & \\
\hline & $(.014)$ & & $(.015)$ & & $(.015)$ & & & \\
\hline \multirow[t]{2}{*}{ Emotional stability } & $.036^{* *}$ & .259 & -.010 & & .007 & & & \\
\hline & $(.014)$ & & $(.016)$ & & $(.016)$ & & & \\
\hline \multirow[t]{2}{*}{ Openness to exp. } & .012 & .257 & -.004 & & .025 & & & \\
\hline & $(.014)$ & & $(.015)$ & & $(.015)$ & & & \\
\hline \multirow[t]{2}{*}{ Locus of control } & $.080^{\star * *}$ & .264 & $.059^{* * *}$ & & $.067^{* * *}$ & & & \\
\hline & $(.014)$ & & $(.015)$ & & $(.015)$ & & & \\
\hline
\end{tabular}

All models are estimated with OLS ( $\mathrm{N}=3,999$ working individuals observed in Wave 12) and control for gender, age, age squared, age cubed, a measure for casual worker, and educational attainment (Base level: Dropping out of high school of finishing year 11). The basic model without cognitive or non-cognitive skills explains $25.7 \%$ of the variation in hourly wages. A test of equality of coefficients on Fraction Answered between column (1) and (2) is not rejected (p-value: 0.1206), while equality of coefficients between columns (1) and (3) is rejected (p-value $<0.001)$. All measures of cognitive ability and non-cognitive skills are standardized to mean 0 and standard deviation 1 . Standard errors are reported in parentheses. ${ }^{* *} \mathrm{p}<0.05,{ }^{* * *} \mathrm{p}<0.01$. 
Table 3: Test of validity of proxy variable Fraction Answered in a wage-regression application

\begin{tabular}{|c|c|c|c|c|c|}
\hline & Model (1) & Model (2) & Diff $^{a}$ & p-value ${ }^{b}$ & $\operatorname{Bias}^{c} \downarrow(\%)$ \\
\hline \multirow[t]{2}{*}{ Years of education } & $.277^{* * *}$ & $.269^{* * *}$ & .00794 & .000512 & 2.870 \\
\hline & $(.0155)$ & $(.0154)$ & & & \\
\hline \multirow[t]{2}{*}{ Extraversion } & $-.0410^{* * *}$ & $-.0403^{* * *}$ & .000719 & .280 & 1.755 \\
\hline & $(.0153)$ & $(.0152)$ & & & \\
\hline \multirow{2}{*}{ Agreeableness } & $-.0594^{* * *}$ & $-.0618^{* * *}$ & -.00240 & .872 & -4.044 \\
\hline & $(.0166)$ & $(.0165)$ & & & \\
\hline \multirow[t]{2}{*}{ Conscientiousness } & -.00578 & -.00553 & .000244 & .429 & 4.229 \\
\hline & $(.0160)$ & $(.0159)$ & & & \\
\hline \multirow[t]{2}{*}{ Emotional stability } & $.101^{* * *}$ & $.103^{* * *}$ & -.00141 & .818 & -1.394 \\
\hline & $(.0170)$ & $(.0169)$ & & & \\
\hline \multirow[t]{2}{*}{ Openness to exp. } & $.175^{* * *}$ & $.172^{* * *}$ & .00379 & .00612 & 2.158 \\
\hline & $(.0163)$ & $(.0162)$ & & & \\
\hline \multirow[t]{2}{*}{ Locus of control } & $.0523^{* * *}$ & $.0467^{* * *}$ & .00561 & .00159 & 10.73 \\
\hline & $(.0162)$ & $(.0161)$ & & & \\
\hline \multirow[t]{2}{*}{ Fraction Answered } & & $.103^{* * *}$ & & & \\
\hline & & $(.0146)$ & & & \\
\hline $\mathrm{R}^{2}$ & 0.160 & 0.170 & & & \\
\hline Observations & 3999 & 3999 & & & \\
\hline
\end{tabular}

All models are estimated with OLS and control for a cubic polynomial of age, gender, and casual worker.

The dependent variable is the first predicted factor of three measures of cognitive ability, and both dependent variable, years of education, and non-cognitive skills are standardized to mean 0 , and standard deviation of 1 .

a Estimated differences and standard errors between absolute values of coefficients obtained from model (1) and model (2). ${ }^{\mathrm{b}}$ the p-value for rejecting the null hypothesis of equality of the coefficients in absolute terms against the alternative hypothesis that the coefficient in Model(1) is greater than that in Model(2), in absolute term. A statistically-significant positive difference indicates that the omitted-variable bias would be larger than the imperfect-proxy bias. ${ }^{c}$ Bias reduction is calculated as the percentage change in the omitted variable bias, calculated as: $\frac{(\mathrm{OVB}-\mathrm{IPB})}{\mathrm{OVB}} * 100 .{ }^{* *} \mathrm{p}<0.05,{ }^{* * *} \mathrm{p}<0.01$. 
Table 4: Effect of Fraction Answered on years of education

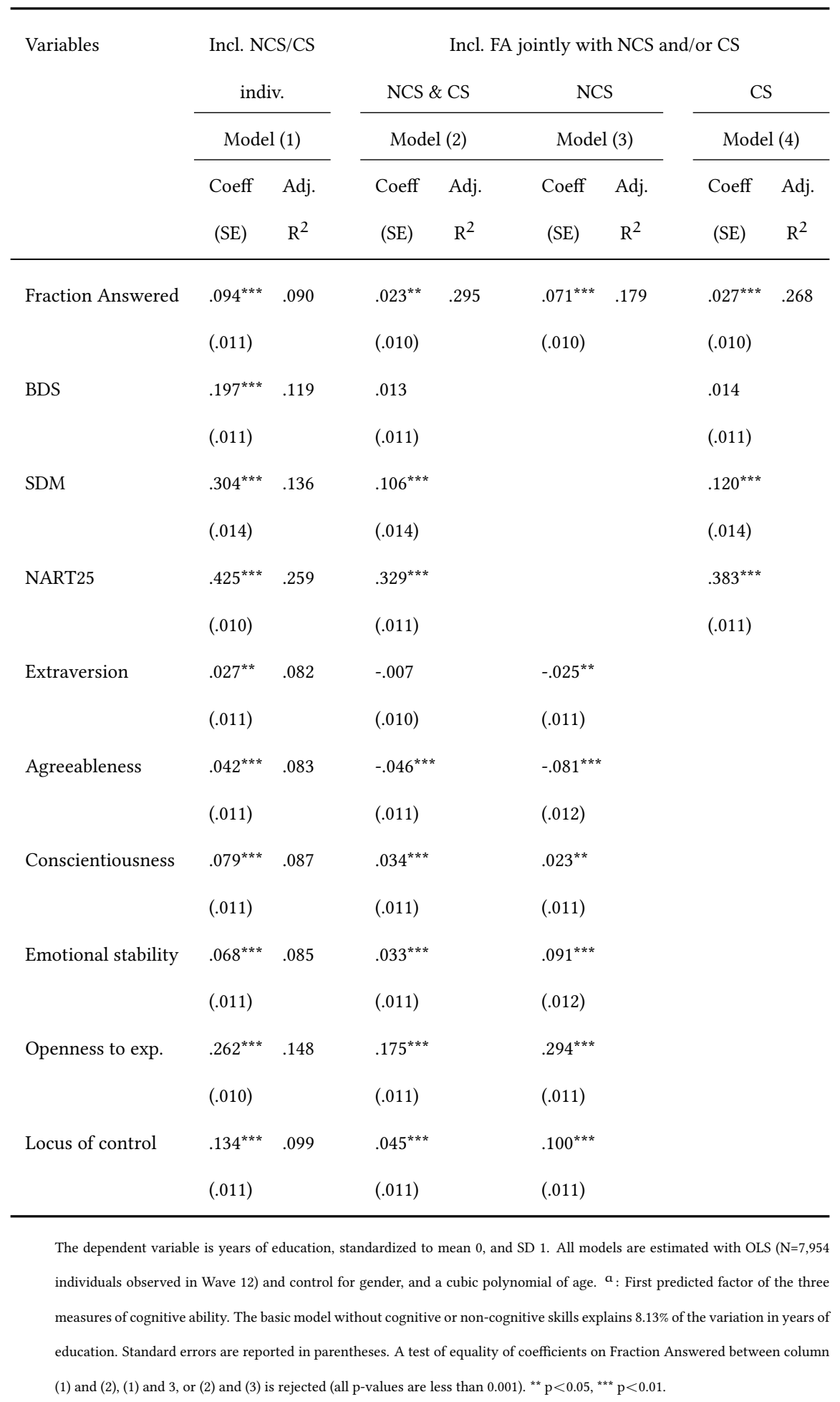


Table 5: Test of validity of proxy variable Fraction Answered in an educational-attainment regression application

\begin{tabular}{|c|c|c|c|c|c|}
\hline & Model (1) & Model (2) & Diff $^{a}$ & $\mathrm{p}$-value ${ }^{\mathrm{b}}$ & $\operatorname{Bias}^{\mathrm{c}} \downarrow(\%)$ \\
\hline Extraversion & $\begin{array}{l}-.0393^{* * *} \\
(.0107)\end{array}$ & $\begin{array}{l}-.0365^{* * *} \\
(.0106)\end{array}$ & .00285 & .0225 & 7.244 \\
\hline Agreeableness & $\begin{array}{l}-.0745^{* * *} \\
(.0116)\end{array}$ & $\begin{array}{l}-.0792^{* * *} \\
(.0115)\end{array}$ & -.00477 & .993 & -6.410 \\
\hline Conscientiousness & $\begin{array}{l}.000670 \\
(.0113)\end{array}$ & $\begin{array}{l}-.00348 \\
(.0112)\end{array}$ & -.00281 & .550 & - \\
\hline Emotional stability & $\begin{array}{l}.138^{* * *} \\
(.0122)\end{array}$ & $\begin{array}{l}.137^{* * *} \\
(.0121)\end{array}$ & .000722 & .328 & .522 \\
\hline Openness to exp. & $\begin{array}{l}.255^{* * *} \\
(.0111)\end{array}$ & $\begin{array}{l}.249^{* * *} \\
(.0110)\end{array}$ & .00656 & .00000162 & 2.571 \\
\hline Locus of control & $\begin{array}{l}.132^{* * *} \\
(.0114)\end{array}$ & $\begin{array}{l}.125^{* * *} \\
(.0113)\end{array}$ & .00622 & .00206 & 4.723 \\
\hline Fraction Answered & & $\begin{array}{l}.132^{* * *} \\
(.0103)\end{array}$ & & & \\
\hline$R^{2}$ & 0.184 & 0.201 & & & \\
\hline Observations & 7954 & 7954 & & & \\
\hline
\end{tabular}

All models are estimated with ordinary least squares and control for a cubic polynomial of age and gender. The dependent variable is the first predicted factor of three measures of cognitive ability, standardized to mean 0 , and standard deviation of 1. ${ }^{a}$ Estimated differences and standard errors between absolute values of coefficients obtained from model (1) and model (2). ${ }^{\mathrm{b}}$ the p-value for rejecting the null hypothesis of equality of the coefficients in absolute terms against the alternative hypothesis that the coefficient in Model(1) is greater than that in Model(2), in absolute term. A statistically-significant positive difference indicates that the omitted-variable bias would be larger than the imperfect-proxy bias. ${ }^{c}$ Bias reduction is calculated as the percentage change in the omitted variable bias, calculated as: $\frac{(\mathrm{O} V \mathrm{~B}-\mathrm{IPB})}{\text { OVB }} * 100 .{ }^{* *} \mathrm{p}<0.05,{ }^{* * *} \mathrm{p}<0.01$ 
Table 6: Relative performance of Fraction Answered as proxy variable for cognitive ability

\begin{tabular}{|c|c|c|c|c|}
\hline Proxy & Ass. (1) & Ass. (2) & Ass. (3) & $\operatorname{Bias}^{c} \downarrow(\%)$ \\
\hline \multirow[t]{3}{*}{ Fraction Answered } & $0.205^{* * *}$ & $\checkmark$ & $\checkmark$ & Yrs education $3 \%$ \\
\hline & & & & Openness $2.2 \%$ \\
\hline & & & & Locus of control $10.7 \%$ \\
\hline \multirow[t]{4}{*}{ Interviewer Rating } & $0.282^{\star * *}$ & $x$ & $\checkmark$ & Yrs education $3 \%$ \\
\hline & & & & Emo. Stab. $5.8 \%$ \\
\hline & & & & Openness $3 \%$ \\
\hline & & & & Locus of control $13 \%$ \\
\hline No matched SCQ & $.0574^{* * *}$ & $\checkmark$ & $x$ & $x$ \\
\hline \multirow[t]{2}{*}{ Time taken for HHQ } & $0.0691^{\star * *}$ & $x$ & $\checkmark$ & Yrs education $<1 \%$ \\
\hline & & & & Locus of control $4.3 \%$ \\
\hline
\end{tabular}




\section{A Online Appendix}

Table 7: Summary statistics

\begin{tabular}{|c|c|c|c|c|c|}
\hline Variable definition & $\mathrm{N}$ & Mean & SD & Min & Max \\
\hline Count non-response & 7954 & 4.34 & 10.48 & 0 & 200 \\
\hline Count required responses & 7954 & 223.71 & 20.95 & 181 & 258 \\
\hline Non-response rate & 7954 & 0.02 & 0.05 & 0 & 0.958 \\
\hline Fraction Answered & 7954 & 0.98 & 0.05 & 0.042 & 1 \\
\hline Age & 7954 & 49.54 & 17.19 & 20 & 100 \\
\hline Male & 7954 & 0.46 & 0.50 & 0 & 1 \\
\hline Backward-Digit-Span (BDS) & 7954 & 3.95 & 1.41 & 0 & 7 \\
\hline Symbol-Digit-Modalities (SDM) & 7954 & 48.31 & 12.93 & 0 & 104 \\
\hline National-Adult-Reading-Test (NART) & 7954 & 14.39 & 5.24 & 0 & 25 \\
\hline Extraversion (Avg Wave 5 and 9) & 7954 & 4.43 & 1.02 & 1.083 & 7 \\
\hline Agreeableness (Avg Wave 5 and 9) & 7954 & 5.38 & 0.83 & 1 & 7 \\
\hline Conscientiousness (Avg Wave 5 and 9) & 7954 & 5.09 & 0.96 & 1 & 7 \\
\hline Emotional stability (Avg Wave 5 and 9) & 7954 & 5.22 & 0.99 & 1.42 & 7 \\
\hline Openness to experience (Avg Wave 5 and 9) & 7954 & 4.22 & 0.98 & 1 & 7 \\
\hline \multicolumn{6}{|l|}{ Locus of control (Avg Wave 3, 4 and 7) } \\
\hline Little control over life & 7954 & 2.752 & 1.244 & 1 & 7 \\
\hline No way to solve problems & 7954 & 2.560 & 1.282 & 1 & 7 \\
\hline Cannot change the important things & 7954 & 2.571 & 1.253 & 1 & 7 \\
\hline Feel helpless & 7954 & 2.508 & 1.267 & 1 & 7 \\
\hline Pushed around & 7954 & 2.613 & 1.325 & 1 & 7 \\
\hline Future depends on me & 7954 & 5.569 & 1.174 & 1 & 7 \\
\hline Can do just about everything & 7954 & 5.348 & 1.187 & 1 & 7 \\
\hline Hourly wages & 3999 & 32.650 & 17.667 & 1.611 & 312.209 \\
\hline Wages \& salary & 3999 & 63567 & 44147 & 991 & 700483 \\
\hline Casual worker & 3999 & 0.184 & 0.388 & 0 & 1 \\
\hline Years of education & 7954 & 12.35 & 2.28 & 8 & 17 \\
\hline Finished Year 11 or less & 7954 & 0.26 & 0.44 & 0 & 1 \\
\hline Finished Year 12 & 7954 & 0.15 & 0.35 & 0 & 1 \\
\hline Certificate III/IV & 7954 & 0.22 & 0.42 & 0 & 1 \\
\hline Diploma (TAFE) & 7954 & 0.10 & 0.30 & 0 & 1 \\
\hline Bachelors degree & 7954 & 0.15 & 0.36 & 0 & 1 \\
\hline Postgraduate qualification & 7954 & 0.12 & 0.32 & 0 & 1 \\
\hline \multicolumn{6}{|l|}{ Interviewer rating of understanding } \\
\hline Excellent & 7954 & .788 & .408 & 0 & 1 \\
\hline Good & 7954 & .194 & .396 & 0 & 1 \\
\hline Fair & 7954 & .015 & .124 & 0 & 1 \\
\hline Poor & 7954 & .001 & .025 & 0 & 1 \\
\hline Very poor & 7954 & .0002 & .015 & 0 & 1 \\
\hline
\end{tabular}




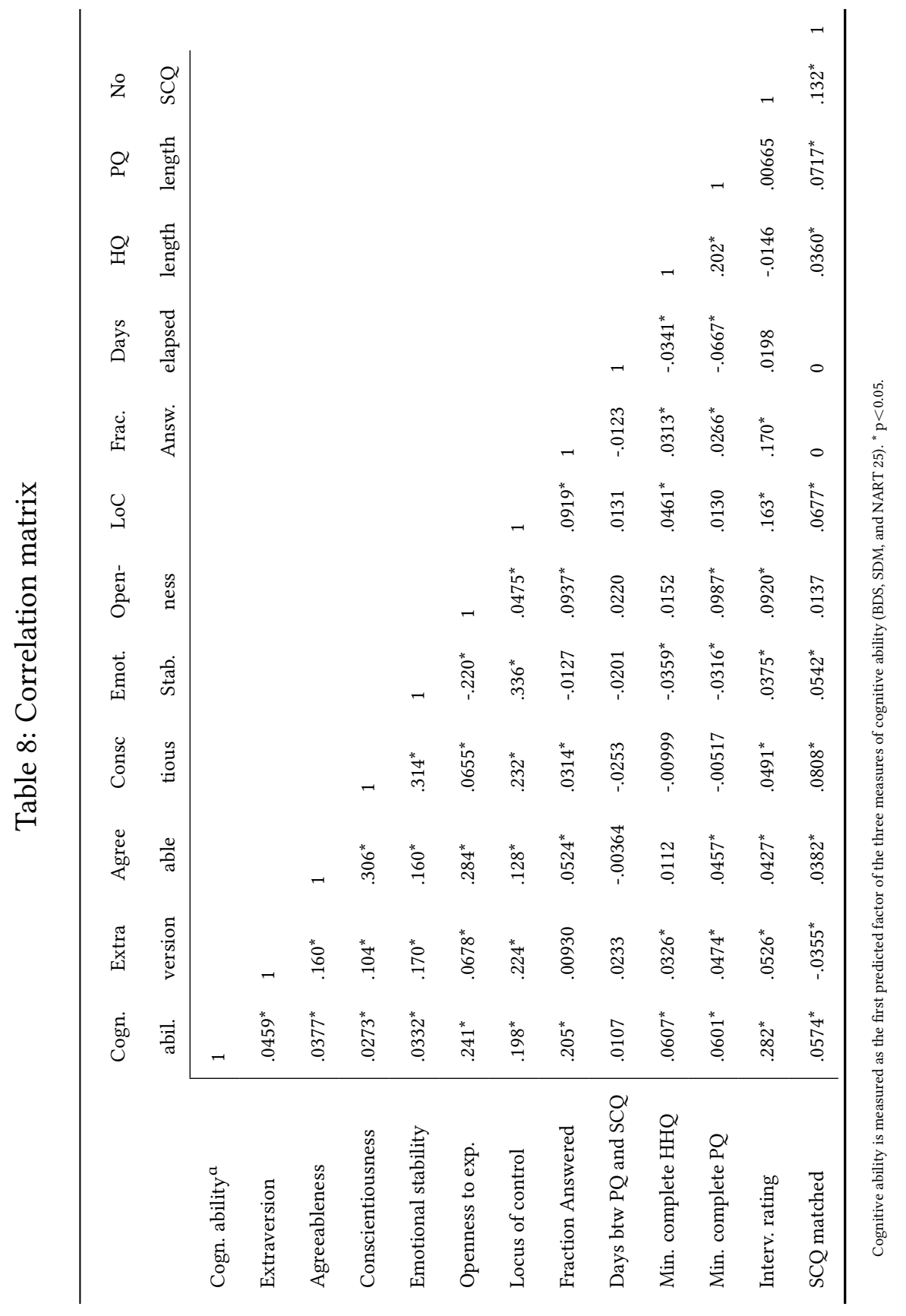


Table 9: Effect of Returning SCQ on log hourly wages

\begin{tabular}{|c|c|c|c|c|c|c|c|c|}
\hline \multirow[t]{5}{*}{ Variables } & \multirow{3}{*}{\multicolumn{2}{|c|}{$\begin{array}{c}\text { Incl. NCS/CS } \\
\text { indiv. } \\
\text { Model (1) }\end{array}$}} & \multicolumn{6}{|c|}{ Incl. FA jointly with NCS and/or CS } \\
\hline & & & \multirow{2}{*}{\multicolumn{2}{|c|}{$\begin{array}{c}\text { NCS \& CS } \\
\text { Model (2) }\end{array}$}} & \multirow{2}{*}{\multicolumn{2}{|c|}{$\begin{array}{c}\text { NCS } \\
\text { Model (3) }\end{array}$}} & \multicolumn{2}{|c|}{$\mathrm{CS}$} \\
\hline & & & & & & & Mode & (4) \\
\hline & \multirow{2}{*}{$\begin{array}{l}\text { Coeff } \\
\text { (SE) }\end{array}$} & \multirow{2}{*}{$\begin{array}{l}\text { Adj. } \\
\mathrm{R}^{2}\end{array}$} & Coeff & Adj. & Coeff & Adj. & Coeff & Adj. \\
\hline & & & (SE) & $\mathrm{R}^{2}$ & (SE) & $\mathrm{R}^{2}$ & (SE) & $\mathrm{R}^{2}$ \\
\hline \multirow[t]{2}{*}{ SCQ matched } & .088 & .262 & .048 & .288 & .066 & .271 & .066 & .281 \\
\hline & $(.059)$ & & $(.058)$ & & $(.059)$ & & $(.058)$ & \\
\hline \multirow[t]{2}{*}{ BDS } & $.060^{* * *}$ & .265 & .008 & & & & .010 & \\
\hline & $(.013)$ & & $(.014)$ & & & & $(.014)$ & \\
\hline \multirow[t]{2}{*}{ SDM } & $.126^{* * *}$ & .275 & $.096^{* * *}$ & & & & $.101^{* * *}$ & \\
\hline & $(.014)$ & & $(.015)$ & & & & $(.015)$ & \\
\hline \multirow[t]{2}{*}{ NART25 } & $.119^{* * *}$ & .273 & $.094^{* * *}$ & & & & $.091^{* * *}$ & \\
\hline & $(.015)$ & & $(.016)$ & & & & $(.016)$ & \\
\hline \multirow[t]{2}{*}{ Extraversion } & $.033^{* *}$ & .263 & .024 & & .017 & & & \\
\hline & $(.013)$ & & $(.014)$ & & $(.014)$ & & & \\
\hline \multirow{2}{*}{ Agreeableness } & -.020 & .262 & $-.036^{* *}$ & & $-.047^{* * *}$ & & & \\
\hline & $(.014)$ & & $(.015)$ & & $(.015)$ & & & \\
\hline \multirow[t]{2}{*}{ Conscientiousness } & $.062^{* * *}$ & .265 & $.052^{* * *}$ & & $.049^{* * *}$ & & & \\
\hline & $(.014)$ & & $(.014)$ & & $(.015)$ & & & \\
\hline \multirow[t]{2}{*}{ Emotional stability } & $.036^{* * *}$ & .263 & -.014 & & .004 & & & \\
\hline & $(.013)$ & & $(.015)$ & & $(.015)$ & & & \\
\hline \multirow[t]{2}{*}{ Openness to exp. } & .007 & .262 & -.010 & & .020 & & & \\
\hline & $(.014)$ & & $(.015)$ & & $(.015)$ & & & \\
\hline \multirow[t]{2}{*}{ Locus of control } & $.082^{* * *}$ & .268 & $.062^{* * *}$ & & $.071^{\star * *}$ & & & \\
\hline & $(.013)$ & & $(.015)$ & & $(.015)$ & & & \\
\hline
\end{tabular}

All models are estimated with OLS ( $\mathrm{N}=4,228$ working individuals observed in Wave 12) and control for gender, age, age squared, age cubed, a measure for casual worker, and educational attainment (Base level: Dropping out of high school of finishing year 11). All measures of cognitive ability and non-cognitive skills are standardized to mean 0 and standard deviation 1 . Standard errors are reported in parentheses. ${ }^{* *} \mathrm{p}<0.05,{ }^{* * *} \mathrm{p}<0.01$ 
Table 10: Test of validity of proxy variable Returning SCQ in a wage-regression application

\begin{tabular}{|c|c|c|c|c|c|}
\hline & Model (1) & Model (2) & Diff $^{a}$ & p-value ${ }^{b}$ & $\operatorname{Bias}^{c}(\%)$ \\
\hline \multirow[t]{2}{*}{ Years of education } & $.280^{* * *}$ & $.280^{* * *}$ & .000246 & .244 & .0877 \\
\hline & $(.0150)$ & $(.0150)$ & & & \\
\hline \multirow[t]{2}{*}{ Extraversion } & $-.0396^{* * *}$ & $-.0391^{* * *}$ & .000493 & .193 & 1.244 \\
\hline & $(.0149)$ & $(.0149)$ & & & \\
\hline \multirow{2}{*}{ Agreeableness } & $-.0561^{* * *}$ & $-.0560^{* * *}$ & .0000915 & .359 & .163 \\
\hline & $(.0161)$ & $(.0161)$ & & & \\
\hline \multirow[t]{2}{*}{ Conscientiousness } & -.00951 & -.0101 & -.000641 & .811 & -6.742 \\
\hline & $(.0156)$ & $(.0156)$ & & & \\
\hline \multirow[t]{2}{*}{ Emotional stability } & $.100^{* * *}$ & $.100^{* * *}$ & .000269 & .237 & .268 \\
\hline & $(.0166)$ & $(.0166)$ & & & \\
\hline \multirow[t]{2}{*}{ Openness to exp. } & $.173^{* * *}$ & $.174^{* * *}$ & -.0000621 & .606 & -.0358 \\
\hline & $(.0159)$ & $(.0159)$ & & & \\
\hline \multirow[t]{2}{*}{ Locus of control } & $.0535^{* * *}$ & $.0531^{* * *}$ & .000460 & .205 & .859 \\
\hline & $(.0157)$ & $(.0157)$ & & & \\
\hline \multirow[t]{2}{*}{ SCQ matched } & & .0593 & & & \\
\hline & & $(.0630)$ & & & \\
\hline $\mathrm{R}^{2}$ & 0.160 & 0.160 & & & \\
\hline Observations & 4228 & 4228 & & & \\
\hline
\end{tabular}

All models are estimated with OLS and control for a cubic polynomial of age, gender, and casual worker

The dependent variable is the first predicted factor of three measures of cognitive ability, and both dependent variable, years of education, and non-cognitive skills are standardized to mean 0 , and standard deviation of

1. ${ }^{a}$ Estimated differences and standard errors between absolute values of coefficients obtained from model (1) and model (2). ${ }^{b}$ the p-value for rejecting the null hypothesis of equality of the coefficients in absolute terms against the alternative hypothesis that the coefficient in Model(1) is greater than that in Model(2), in absolute term. A statistically-significant positive difference indicates that the omitted-variable bias would be larger than the imperfect-proxy bias. ${ }^{c}$ Bias reduction is calculated as the percentage change in the omitted variable bias, calculated as: $\frac{(\mathrm{O} V \mathrm{~B}-\mathrm{IPB})}{\text { OVB }} * 100 .{ }^{* *} \mathrm{p}<0.05,{ }^{* * *} \mathrm{p}<0.01$ 
Table 11: Effect of Interviewer Rating on log hourly wages

\begin{tabular}{|c|c|c|c|c|c|c|c|c|}
\hline \multirow[t]{5}{*}{ Variables } & \multirow{2}{*}{\multicolumn{2}{|c|}{$\begin{array}{c}\text { Incl. NCS/CS } \\
\text { indiv. }\end{array}$}} & \multicolumn{6}{|c|}{ Incl. FA jointly with NCS and/or CS } \\
\hline & & & NCS \& & $\mathrm{CS}$ & $\mathrm{NC}$ & & CS & \\
\hline & \multicolumn{2}{|c|}{ Model (1) } & \multicolumn{2}{|c|}{ Model (2) } & \multicolumn{2}{|c|}{ Model (3) } & \multicolumn{2}{|c|}{ Model (4) } \\
\hline & Coeff & Adj. & Coeff & Adj. & Coeff & Adj. & Coeff & Adj. \\
\hline & (SE) & $\mathrm{R}^{2}$ & (SE) & $\mathrm{R}^{2}$ & (SE) & $\mathrm{R}^{2}$ & (SE) & $\mathrm{R}^{2}$ \\
\hline \multirow[t]{2}{*}{ Interv. rating } & $.158^{* * *}$ & .266 & $.091^{* * *}$ & .290 & $.143^{* * *}$ & .274 & $.102^{* * *}$ & .283 \\
\hline & $(.032)$ & & $(.032)$ & & $(.032)$ & & $(.032)$ & \\
\hline \multirow[t]{2}{*}{ BDS } & $.060^{* * *}$ & .265 & .008 & & & & .010 & \\
\hline & $(.013)$ & & $(.014)$ & & & & $(.014)$ & \\
\hline \multirow[t]{2}{*}{ SDM } & $.126^{* * *}$ & .275 & $.093^{* * *}$ & & & & $.097^{* * *}$ & \\
\hline & $(.014)$ & & $(.015)$ & & & & $(.015)$ & \\
\hline \multirow[t]{2}{*}{ NART25 } & $.119^{* * *}$ & .273 & $.088^{* * *}$ & & & & $.084^{* * *}$ & \\
\hline & $(.015)$ & & $(.016)$ & & & & $(.016)$ & \\
\hline \multirow[t]{2}{*}{ Extraversion } & $.033^{* *}$ & .263 & .023 & & .015 & & & \\
\hline & $(.013)$ & & $(.014)$ & & $(.014)$ & & & \\
\hline \multirow[t]{2}{*}{ Agreeableness } & -.020 & .262 & $-.036^{* *}$ & & $-.046^{* * *}$ & & & \\
\hline & $(.014)$ & & $(.015)$ & & $(.015)$ & & & \\
\hline \multirow[t]{2}{*}{ Conscientiousness } & $.062^{* * *}$ & .265 & $.053^{\star * *}$ & & $.050^{\star * *}$ & & & \\
\hline & $(.014)$ & & $(.014)$ & & $(.014)$ & & & \\
\hline \multirow[t]{2}{*}{ Emotional stability } & $.036^{* * *}$ & .263 & -.015 & & .002 & & & \\
\hline & $(.013)$ & & $(.015)$ & & $(.015)$ & & & \\
\hline \multirow[t]{2}{*}{ Openness to exp. } & .007 & .262 & -.010 & & .018 & & & \\
\hline & $(.014)$ & & $(.015)$ & & $(.015)$ & & & \\
\hline \multirow[t]{2}{*}{ Locus of control } & $.082^{\star * *}$ & .268 & $.061^{* * *}$ & & $.068^{\star * *}$ & & & \\
\hline & $(.013)$ & & $(.015)$ & & $(.015)$ & & & \\
\hline
\end{tabular}

All models are estimated with OLS ( $\mathrm{N}=4,228$ working individuals observed in Wave 12) and control for gender, age, age squared, age cubed, a measure for casual worker, and educational attainment (Base level: Dropping out of high school of finishing year 11). All measures of cognitive ability and non-cognitive skills are standardized to mean 0 and standard deviation 1 . Standard errors are reported in parentheses. ${ }^{* *} \mathrm{p}<0.05,{ }^{* * *} \mathrm{p}<0.01$ 
Table 12: Test of validity of proxy variable Interviewer Rating in a wage-regression application

\begin{tabular}{|c|c|c|c|c|c|}
\hline & Model (1) & Model (2) & Diff $^{a}$ & $\mathrm{p}$-value $\mathrm{b}^{\mathrm{b}}$ & $\operatorname{Bias}^{c}(\%)$ \\
\hline \multirow[t]{2}{*}{ Years of education } & $.280^{* * *}$ & $.272^{* * *}$ & .00826 & .000418 & 2.946 \\
\hline & $(.0150)$ & $(.0149)$ & & & \\
\hline \multirow[t]{2}{*}{ Extraversion } & $-.0396^{* * *}$ & $-.0412^{* * *}$ & -.00157 & .785 & -3.969 \\
\hline & $(.0149)$ & $(.0148)$ & & & \\
\hline \multirow[t]{2}{*}{ Agreeableness } & $-.0561^{* * *}$ & $-.0535^{* * *}$ & .00262 & .125 & 4.669 \\
\hline & $(.0161)$ & $(.0160)$ & & & \\
\hline \multirow[t]{2}{*}{ Conscientiousness } & -.00951 & -.00964 & -.000133 & .525 & -1.401 \\
\hline & $(.0156)$ & $(.0155)$ & & & \\
\hline \multirow[t]{2}{*}{ Emotional stability } & $.100^{* * *}$ & $.0945^{* * *}$ & .00585 & .00743 & 5.828 \\
\hline & $(.0166)$ & $(.0165)$ & & & \\
\hline \multirow[t]{2}{*}{ Openness to exp. } & $.173^{* * *}$ & $.168^{* * *}$ & .00522 & .0109 & 3.011 \\
\hline & $(.0159)$ & $(.0157)$ & & & \\
\hline \multirow[t]{2}{*}{ Locus of control } & $.0535^{* * *}$ & $.0466^{* * *}$ & .00698 & .00291 & 13.03 \\
\hline & $(.0157)$ & $(.0156)$ & & & \\
\hline \multirow[t]{2}{*}{ Interv. rating } & & $.316^{* * *}$ & & & \\
\hline & & $(.0337)$ & & & \\
\hline $\mathrm{R}^{2}$ & 0.160 & 0.177 & & & \\
\hline Observations & 4228 & 4228 & & & \\
\hline \multicolumn{6}{|c|}{ All models are estimated with OLS and control for a cubic polynomial of age, gender, and casual worker. The } \\
\hline \multicolumn{6}{|c|}{ dependent variable is the first predicted factor of three measures of cognitive ability, and both dependent } \\
\hline \multicolumn{6}{|c|}{ variable, years of education, and non-cognitive skills are standardized to mean 0 , and standard deviation of } \\
\hline \multicolumn{6}{|c|}{ 1. ${ }^{a}$ Estimated differences and standard errors between absolute values of coefficients obtained from model } \\
\hline \multicolumn{6}{|c|}{ (1) and model (2). ${ }^{b}$ the p-value for rejecting the null hypothesis of equality of the coefficients in absolute } \\
\hline \multicolumn{6}{|c|}{ terms against the alternative hypothesis that the coefficient in $\operatorname{Model}(1)$ is greater than that in $\operatorname{Model}(2)$, in } \\
\hline \multicolumn{6}{|c|}{ absolute term. A statistically-significant positive difference indicates that the omitted-variable bias would be } \\
\hline \multicolumn{6}{|c|}{ larger than the imperfect-proxy bias. ${ }^{c}$ Bias reduction is calculated as the percentage change in the omitted } \\
\hline variable bias, calculc & $s: \frac{(\mathrm{OVB}-}{\mathrm{OV}}$ & B) $* 100 . * *$ & $5,{ }^{* * *} \mathrm{p}$ & & \\
\hline
\end{tabular}


Table 13: Effect of HHQ length on log hourly wages

\begin{tabular}{|c|c|c|c|c|c|c|c|c|}
\hline \multirow[t]{5}{*}{ Variables } & \multirow{2}{*}{\multicolumn{2}{|c|}{$\begin{array}{c}\text { Incl. NCS/CS } \\
\text { indiv. }\end{array}$}} & \multicolumn{6}{|c|}{ Incl. FA jointly with NCS and/or CS } \\
\hline & & & NCS \& & $\mathrm{CS}$ & $\mathrm{NCS}$ & & $\mathrm{CS}$ & \\
\hline & \multicolumn{2}{|c|}{ Model (1) } & \multicolumn{2}{|c|}{ Model (2) } & \multicolumn{2}{|c|}{ Model (3) } & \multicolumn{2}{|c|}{ Model (4) } \\
\hline & Coeff & Adj. & Coeff & Adj. & Coeff & Adj. & Coeff & Adj. \\
\hline & (SE) & $\mathrm{R}^{2}$ & (SE) & $\mathrm{R}^{2}$ & (SE) & $\mathrm{R}^{2}$ & (SE) & $\mathrm{R}^{2}$ \\
\hline \multirow[t]{2}{*}{ Min. complete HHQ } & $.048^{* * *}$ & .264 & $.039^{* * *}$ & .290 & $.045^{* * *}$ & .273 & $.042^{* * *}$ & .283 \\
\hline & $(.014)$ & & $(.014)$ & & $(.014)$ & & $(.014)$ & \\
\hline \multirow[t]{2}{*}{ BDS } & $.059^{* * *}$ & .265 & .006 & & & & .008 & \\
\hline & $(.013)$ & & $(.014)$ & & & & $(.014)$ & \\
\hline \multirow[t]{2}{*}{ SDM } & $.128^{* * *}$ & .275 & $.097^{* * *}$ & & & & $.102^{* * *}$ & \\
\hline & $(.015)$ & & $(.015)$ & & & & $(.015)$ & \\
\hline \multirow[t]{2}{*}{ NART25 } & $.121^{* * *}$ & .273 & $.094^{* * *}$ & & & & $.091^{* * *}$ & \\
\hline & $(.015)$ & & $(.016)$ & & & & $(.016)$ & \\
\hline \multirow[t]{2}{*}{ Extraversion } & $.031^{* *}$ & .262 & .020 & & .012 & & & \\
\hline & $(.013)$ & & $(.014)$ & & $(.014)$ & & & \\
\hline \multirow[t]{2}{*}{ Agreeableness } & -.019 & .262 & $-.035^{* *}$ & & $-.046^{* * *}$ & & & \\
\hline & $(.014)$ & & $(.015)$ & & $(.015)$ & & & \\
\hline \multirow[t]{2}{*}{ Conscientiousness } & $.062^{* * *}$ & .265 & $.055^{* * *}$ & & $.052^{* * *}$ & & & \\
\hline & $(.014)$ & & $(.014)$ & & $(.015)$ & & & \\
\hline \multirow[t]{2}{*}{ Emotional stability } & $.036^{* * *}$ & .263 & -.013 & & .006 & & & \\
\hline & $(.014)$ & & $(.015)$ & & $(.016)$ & & & \\
\hline \multirow[t]{2}{*}{ Openness to exp. } & .008 & .262 & -.008 & & .023 & & & \\
\hline & $(.014)$ & & $(.015)$ & & $(.015)$ & & & \\
\hline \multirow[t]{2}{*}{ Locus of control } & $.082^{* \star *}$ & .268 & $.061^{* * *}$ & & $.069^{* * *}$ & & & \\
\hline & $(.013)$ & & $(.015)$ & & $(.015)$ & & & \\
\hline
\end{tabular}

All models are estimated with OLS ( $\mathrm{N}=4,228$ working individuals observed in Wave 12) and control for gender, age, age squared, age cubed, a measure for casual worker, and educational attainment (Base level: Dropping out of high school of finishing year 11).

All measures of cognitive ability and non-cognitive skills are standardized to mean 0 and standard deviation 1 . Standard errors are reported in parentheses. ${ }^{* *} \mathrm{p}<0.05,{ }^{* * *} \mathrm{p}<0.01$. 
Table 14: Test of validity of proxy variable HHQ length in a wage-regression application

\begin{tabular}{|c|c|c|c|c|c|}
\hline & Model (1) & Model (2) & Diff $^{a}$ & $\mathrm{p}$-value ${ }^{b}$ & $\operatorname{Bias}^{c}(\%)$ \\
\hline \multirow[t]{2}{*}{ Years of education } & $.280^{* * *}$ & $.278^{* * *}$ & .00221 & .0121 & .788 \\
\hline & $(.0151)$ & $(.0151)$ & & & \\
\hline \multirow[t]{2}{*}{ Extraversion } & $-.0406^{* * *}$ & $-.0420^{\star * *}$ & -.00147 & .958 & -3.629 \\
\hline & $(.0150)$ & $(.0150)$ & & & \\
\hline \multirow[t]{2}{*}{ Agreeableness } & $-.0573^{* * *}$ & $-.0567^{* * *}$ & .000603 & .203 & 1.052 \\
\hline & $(.0162)$ & $(.0162)$ & & & \\
\hline \multirow[t]{2}{*}{ Conscientiousness } & -.0102 & -.00916 & .00105 & .0691 & 10.28 \\
\hline & $(.0157)$ & $(.0157)$ & & & \\
\hline \multirow[t]{2}{*}{ Emotional stability } & $.101^{* * *}$ & $.103^{* * *}$ & -.00165 & .965 & -1.636 \\
\hline & $(.0167)$ & $(.0167)$ & & & \\
\hline \multirow[t]{2}{*}{ Openness to exp. } & $.174^{* * *}$ & $.175^{* * *}$ & -.00129 & .945 & -.743 \\
\hline & $(.0160)$ & $(.0160)$ & & & \\
\hline \multirow[t]{2}{*}{ Locus of control } & $.0557^{* * *}$ & $.0533^{* * *}$ & .00243 & .00751 & 4.353 \\
\hline & $(.0158)$ & $(.0158)$ & & & \\
\hline \multirow[t]{2}{*}{ Min. complete HHQ } & & $.0411^{* * *}$ & & & \\
\hline & & $(.0147)$ & & & \\
\hline $\mathrm{R}^{2}$ & 0.159 & 0.161 & & & \\
\hline Observations & 4189 & 4189 & & & \\
\hline
\end{tabular}

\footnotetext{
All models are estimated with OLS and control for a cubic polynomial of age, gender, and casual worker. The dependent variable is the first predicted factor of three measures of cognitive ability, and both dependent variable, years of education, and non-cognitive skills are standardized to mean 0 , and standard deviation of 1. a Estimated differences and standard errors between absolute values of coefficients obtained from model (1) and model (2). ${ }^{b}$ the p-value for rejecting the null hypothesis of equality of the coefficients in absolute terms against the alternative hypothesis that the coefficient in Model(1) is greater than that in Model(2), in absolute term. A statistically-significant positive difference indicates that the omitted-variable bias would be larger than the imperfect-proxy bias. ${ }^{c}$ Bias reduction is calculated as the percentage change in the omitted variable bias, calculated as: $\frac{(\mathrm{O} V \mathrm{~B}-\mathrm{IPB})}{\text { OVB }} * 100 .{ }^{* *} \mathrm{p}<0.05,{ }^{* * *} \mathrm{p}<0.01$.
} 
Proof 15: Omitted Variable Bias in the Multivariate Case

$$
Y_{i}=\beta_{0}+\beta_{1} \mathrm{EDU}_{i}+\beta_{2} \mathrm{NCS}_{i}+\beta_{3} C S_{i}+u_{i}
$$

If we would omit $C S_{i}$, we would estimate the following equation instead:

$$
Y_{i}=\beta_{0}^{\prime}+\beta_{1}^{\prime} \mathrm{EDU}_{i}+\beta_{2}^{\prime} \mathrm{NCS}_{i}+u_{i}^{\prime}
$$

However, $C S_{i}$ is related to the other regressors:

$$
\mathrm{CS}_{i}=\gamma_{0}+\gamma_{1} \mathrm{EDU}_{i}+\gamma_{2} \mathrm{NCS}_{i}+v_{i}
$$

By plugging in $C S_{i}$ in Eq. (17), we get the following:

$$
\begin{aligned}
Y_{i} & =\beta_{0}+\beta_{1} \operatorname{EDU}_{i}+\beta_{2} \operatorname{NCS}_{i}+\beta_{3}\left(\gamma_{0}+\gamma_{1} \operatorname{EDU}_{i}+\gamma_{2} \operatorname{NCS}_{i}+v_{i}\right)+u_{i} . \\
& =\underbrace{\left(\beta_{0}+\beta_{3} \gamma_{0}\right)}_{\hat{\beta}_{0}^{\prime}}+\underbrace{\left(\beta_{1}+\beta_{3} \gamma_{1}\right)}_{\hat{\beta}_{1}^{\prime}} \operatorname{EDU}_{i}+\underbrace{\left(\beta_{2}+\beta_{3} \gamma_{2}\right)}_{\hat{\beta}_{2}^{\prime}} \operatorname{NCS}_{i}+\underbrace{\beta_{3} v_{i}+u_{i}}_{\hat{u}_{i}^{\prime}} .
\end{aligned}
$$

Hence, $\hat{\beta_{0}^{\prime}}$ is an estimate of $\left(\beta_{0}+\beta_{3} \gamma_{0}\right)$ instead of $\beta_{0}^{\prime}, \hat{\beta_{1}^{\prime}}$ is an estimate of $\left(\beta_{1}+\beta_{3} \gamma_{1}\right)$ instead of $\beta_{1}, \hat{\beta_{2}^{\prime}}$ is an estimate of $\left(\beta_{2}+\beta_{3} \gamma_{2}\right)$ instead of $\beta_{2}$ and $\hat{u}_{i}^{\prime}$ is an estimate of $\left(\beta_{3} v_{i}+u_{i}\right)$ instead of $u_{i}^{\prime}$. The biases for our coefficient of interest are therefore:

$$
\begin{aligned}
& \hat{\beta_{1}}-\beta_{1}=\beta_{1}+\beta_{3} \gamma_{1}-\beta_{1}=\beta_{3} \gamma_{1} \\
& \hat{\beta_{2}}-\beta_{2}=\beta_{2}+\beta_{3} \gamma_{3}-\beta_{2}=\beta_{3} \gamma_{2}
\end{aligned}
$$

